\title{
ResearchOnline@JCU
}

This is the Accepted Version of a paper published in the journal Current Drug Targets:

Emeto, Theophilus I., Seto, Sai-Wang, and Golledge, Jonathan (2014) Targets for medical therapy to limit abdominal aortic aneurysm progression. Current Drug Targets, 15 (9). pp. 860-873.

http://dx.doi.org/10.2174/1389450115666140804155036 


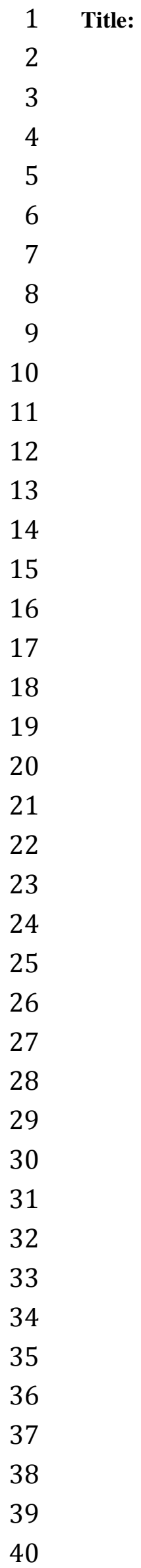


Title page:

42

Targets for medical therapy to limit abdominal aortic aneurysm progression

${ }^{1}$ The Vascular Biology Unit, Queensland Research Centre for Peripheral Vascular Disease, School of

Medicine and Dentistry, James Cook University, James Cook Drive, Douglas, Townsville, QLD 4811,

Australia

${ }^{2}$ Discipline of Public Health and Tropical Medicine, School of Public Health, Tropical Medicine and

Rehabilitation Sciences, James Cook University, James Cook Drive, Douglas, Townsville, QLD 4811,

${ }^{3}$ Department of Vascular and Endovascular Surgery, The Townsville Hospital, Townsville, QLD 4814,

Running Title - Emeto- Drug development in abdominal aortic aneurysm

62 University Townsville, QLD, Australia 4811. Fax +61 747961401 Telephone +61 747961417 Email: 
77 Abstract

Abdominal aortic aneurysm (AAA) is an important cause of mortality in older adults. Most AAAs are

80 asymptomatic and screening programs have been introduced to identify AAAs at an early stage in some

81 countries. There is currently no accepted therapy for early stage or small AAAs, which are frequently

82 identified by such programs. In this review we discuss work underway to identify targets for medical

83 treatments to limit progression of small AAAs. Specifically we discuss studies, which have examined

84 the potential of targeting inflammation, proteolysis, the renin angiotensin system, the coagulation

85 system and sex hormones on AAA pathogenesis. As yet none of the treatment targets have translated

86 into an agent, which can effectively reduce AAA progression in clinical practice.

87

88

89

90

91

92

93

94

95

96

97

98

99

100

101

102

103

104

105

106 
108 Abdominal aortic aneurysm (AAA) is a common degenerative disease of the aorta particularly 109 affecting people aged $>65$ years.(1-4) AAA is usually asymptomatic unless rupture occurs which is 110 frequently fatal.(1, 2) AAA is also associated with a higher risk of other major cardiovascular 111 events.(5) It has been reported for example, that over $45 \%$ of patients with small AAAs die secondary 112 to myocardial infarction and stroke.(6) The primary focus of treatment is to prevent AAA rupture since 113 this is the main recognised complication of this problem. Aortic dilatation is usually progressive and 114 there is an absence of effective medications to limit aneurysm progression.(5, 7) Current guidelines 115 indicate that patients with large AAAs $(>50-55 \mathrm{~mm})$ should be considered for endovascular or open 116 surgical repair.(7, 8) In patients with smaller AAAs, where surgical intervention is not recommended, 117 regular clinical review and ultrasound monitoring of aortic diameter is recommended because of the 118 lack of approved effective non-surgical interventional options for the disease.(9) Up to 60\% of small 119 AAAs undergoing monitoring expand to a size requiring surgical repair.(5, 10, 11) The development of 120 medications that can effectively limit the number of patients requiring AAA surgery would have 121 potential patient and cost benefits. In this article we outline current progress in developing 122 pharmacotherapy for AAA.

\section{AAA Pathology}

125 AAA is generally accepted to be a complex disease due to aberrant interactions between environmental risk factors and genetic predisposition which exacerbate the normal ageing processes.(5) Once initiated, AAA is characterised by a number of key features. These include significant remodelling and degradation of the extracellular matrix (ECM) by proteolytic enzymes such as matrix metalloproteinases (MMPs),(12, 13) significant reductions in vascular smooth muscles (VSMC) density $(14,15)$ and chronic inflammation denoted by invasion of the tunica media by macrophages and mononuclear lymphocytes.(16-21) Intraluminal thrombus (ILT) and vascular calcifications are usually associated with AAA and have been implicated in AAA formation,(22, 23) progression,(24-27) and rupture.(18, 27-31) Localised hypoxia and increased wall stress have been reported within areas of the aorta covered by ILT.(32) Neutrophil gelatinase associated lipocalin (NGAL) found in all layers of

135 ILT,(30)is reported to prevent MMP-9 inactivation,(33) and the NGAL-MMP-9 complex has been suggested to encourage the proteolytic degradation of the ECM.(30) ILT promotes the migration of inflammatory cells such as neutrophils(30), macrophages and T-lymphocytes,(18) which can potentially promote VSMC apoptosis and thinning of the aortic wall.(18) This presence of effector immune cells and their products together with observed immunoreactivity of IgG purified from AAA

140 tissue to ECM proteins suggests an autoimmune aspect to AAA formation.(5, 34, 35) However, once 141 triggered, alterations within the aortic wall most likely continue in a vicious cycle ending in 142 progressive loss of normal ECM configuration and phenotypic modulation of VSMC.(36)

143 Because of the difficulty associated with obtaining human AAA tissue biopsies (most patients undergo 144 endovascular aneurysm repair rather than open surgery),(37) and the fact that these biopsies are usually 
obtained at the end-stage of disease progression, much of the knowledge gained about AAA has been obtained from animal models.(38, 39) In some cases, investigations have been supplemented by using explant culture of human samples.(1, 40-42) The animal models and the ex-vivo studies have been used extensively to screen putative therapeutic targets for AAA.(1, 41, 43-46)

\section{Putative therapeutic strategies}

A number of therapeutic strategies for AAA have been researched in both pre-clinical and clinical studies in the past decade (Figure 1). These include investigations into pathways implicated in AAA pathogenesis such as the renin-angiotensin system (RAS), inflammatory pathways, intracellular signalling pathways, and agents known to affect some or all of the aforementioned processes such as sex hormones, cholesterol lowering agents, protease inhibitors, immune cell modulators and antiplatelet therapy.

\subsection{The RAS}

The RAS is an important regulator of cardiovascular homeostasis.(47) The RAS has been implicated in ECM remodelling,(36) and inflammatory pathways involved in AAA formation in animal models.(38, 47-49) The key peptide in the RAS is the octapeptide angiotensin II (Ang II), which is known to exert its proinflammatory effects by inducing the expression of several chemokines and adhesion molecules.(41, 50,51) Continuous infusion of Ang II has been widely reported to result in AAA in the pro-atherosclerotic hyperlipidaemic apolipoprotein $\mathrm{E}$ deficient (Apo- ${ }^{-/}$) mouse.(48, 50, 52) In addition, a number of studies have implicated the RAS in human AAA pathogenesis.(53-56) The activities of the Ang II forming enzymes, angiotensin converting enzyme (ACE) and chymase have been reported to be upregulated in the aneurysmal aorta.(55, 56) Therefore, there has been a lot of interest in targeting the RAS pathway as a putative treatment for AAA. Consequently, ACE inhibitors and Ang II receptor blockers (ARB) have been investigated in several studies as putative pharmacological therapies for AAA. These drugs are already established as being beneficial in treating hypertension and heart failure. $(57,58)$

Three ACE inhibitors (enalapril, captopril and Lisinopril) but not the angiotensin receptor blocker, losartan were reported to inhibit AAA development in the elastase infused rat model of AAA.(59) These medications were shown to attenuate aortic media elastin degradation independent of their effect on blood pressure and without diminishing the elastase-induced inflammatory response.(59) In contrast, Daugherty et al. demonstrated that losartan inhibited Ang II-induced AAA in ApoE ${ }^{-/-}$ mice.(60) The discrepant effect of losartan on AAA formation suggests that ARBs exert different effects depending on the animal model. However, Fujiwara and colleagues reported that another ARB, valsartan inhibited AAA development in the elastase-induced AAA rat model independent of its antihypertensive effect.(61) They showed that valsartan inhibited nuclear factor- $\kappa B$ (NF- $\kappa B$ )

182 activation, macrophage infiltration, and MMP-2 and -9 expression.(61) Recently, employing the Ang 

significantly inhibited AAA progression and reduced aortic arch atherosclerosis.(43) Aliskiren was also found to reduce aortic pro-renin receptor expression, mitogen-activated protein kinase activity, and aortic inflammation.(43)

Human studies are also contradictory. For example, in a population based case-control study, ACE inhibitor but not ARB prescription were reported to be significantly associated with a decreased risk of AAA rupture.(63) Contrary to this, Sweeting and colleagues reported an increased risk of aortic expansion in patients receiving ACE inhibitors in a prospective cohort study of patients enrolled in the UK small aneurysm trial.(64) Thus, there is conflicting evidence on the potential beneficial or detrimental effects of targeting the RAS for AAA therapy. There are a number of on-going clinical trials examining the effect of blocking the RAS on small AAA progression.(37) Examples of animal and human association studies linking the RAS with AAA are shown in Table 1.

\subsection{Sex hormones}

Until recently, it has been widely accepted that the female sex confers some form of protection from AAA. $(65,66)$ The predilection of AAA for the males and emerging data linking estrogen and estrogen receptor modulation with reduced inflammation in women,(67) has resulted in a number of studies investigating the effect of gonadal hormones on AAA pathogenesis (Table 2). For example, Ailawadi et al. reported that 17ß-estradiol inhibited AAA development in an elastase rat model associated with decreased aortic medial macrophage infiltration, and lower MMP-9 concentrations.(68) MartinMcNulty and colleagues demonstrated a reduction in AAA size in mice receiving $17 \beta$-estradiol characterised by decreased expression of monocyte chemoattractant protein-1 (MCP-1), and NF-кB activity in the Ang II-infused mouse model of AAA.(69) In a separate study, Grigoryants et al. demonstrated that the selective estrogen receptor modulator, tamoxifen significantly reduced AAA, MMP-9 expression and inflammatory neutrophil infiltration in an elastase-induced AAA rat model.(70) This effect was partially abrogated by a catalase inhibitor suggesting that the superoxide pathway was involved. The effect of gonadal hormones on AAA development in animal models is not completely

211 consistent. Henriques and colleagues reported that ovariectomy in female mice did not result in increased AAA formation whereas orchidectomy reduced aneurysm size in male mice in the Ang II-

213 induced model of AAA.(71) Collectively, these data suggest that gonadal hormones may play a role in

214 AAA formation; however more work is needed to clarify a safe and effective target for AAA therapy.

\subsection{Inflammatory pathways}

217 AAA is regarded as the consequence of a chronic inflammatory process due to the intense 218 inflammation seen within AAA wall biopsies.(1, 44, 72, 73) A number of proinflammatory factors, 219 such as reactive oxygen species (ROS), interleukin-6 (IL-6), MCP-1, and tumor necrosis factor- $\alpha$ 220 (TNF- $\alpha$ ) have been implicated in AAA pathogenesis. $(74,75)$ In addition, prostaglandins, a group of 221 lipid autacoids derived from arachidonic acid and cyclooxygenase have been implicated in aortic 
medial degradation through the production of MMPs.(76, 77) Evidence suggests that both prostaglandin E2 ( $\left.\mathrm{PGE}_{2}\right)$ and cyclooxygenase-2 (COX-2) are significantly upregulated in aneurysmal tissue and encourages VSMC apoptosis.(78-81) Consequently, medication designed to inhibit the inflammatory process has been studied as a means of deterring AAA expansion.

A number of studies examining the therapeutic potential of cyclooxygenase inhibitors in limiting AAA development have been described. For example, the selective COX-2 inhibitor celecoxib, a sulfonamide nonsteroidal anti-inflammatory drug (NSAID) was shown to decrease the incidence and severity of AAA in the Ang II-induced mouse model.(45) In addition, Gitlin et al. demonstrated that COX-2 deficient mice infused with Ang II failed to develop AAA.(82) These data suggest that COX-2 may serve as a putative pharmacotherapeutic target for AAA.

Indomethacin, another NSAID, have been demonstrated in two separate studies utilising an elastaseinduced rat model of AAA to significantly inhibit $\mathrm{PGE}_{2}$ and MMP-9 expression thereby maintaining elastin integrity and decreasing AAA expansion with no effect on the inflammatory infiltrate.(83, 84) Furthermore, Walton et al. demonstrated a significant reduction in AAA growth rate in patients receiving NSAIDs in a small case-control study involving 15 patients receiving NSAIDs and 63 patients without NSAIDs.(81) Concerns regarding the safety of cyclooxygenase inhibitors particularly their association with increased incidence of major cardiovascular events including myocardial infarction and stroke, $(85,86)$ may deter further investigation of these agents as potential therapeutic targets for AAA.

244 A number of agents modulating ROS production have been investigated including vitamin E ( $\alpha$ 245 Tocopherol), a lipid-soluble antioxidant (reviewed in detail by Singh et al.).(87) Vitamin E is reported 246 to inhibit the release of ROS, attenuate proinflammatory cytokine and chemokine release, and regress the expression of vascular cell adhesion molecule-1 (VCAM-1), E-selectin, and intercellular adhesion molecule-1 (ICAM-1). Vitamin E is also reported to inhibit cyclooxygenase expression by monocytes thereby abrogating $\mathrm{PGE}_{2}$ synthesis.(87) It has been reported that vitamin $\mathrm{E}$ inhibits AAA formation in two different rodent models of AAA.(88, 89) Gavrila et al. reported reduced levels of ROS and aortic macrophage infiltration along with reduction in maximum AAA diameter and incidence of rupture in mice receiving vitamin E in a study employing the Ang II-induced mouse model of AAA.(89) Similarly, Nakahashi and colleagues reported that rats receiving vitamin E had significantly decreased

254 AAA expansion rate compared to controls in the elastase-induced rat model of AAA.(88) However, $a$ randomised double-blind placebo-controlled trial by Tornwall et al. suggested that vitamin $E$ and $\beta$ carotene supplements did not reduce the incidence of AAA diagnosis or rupture in patients.(90)

A number of immune suppressants have been investigated as potential therapies for AAA. For 259 example, rapamycin (sirolimus) an mTOR inhibitor used extensively in kidney transplants and in 260 vascular stents to avert intimal hyperplasia,(91, 92) was shown to significantly reduce AAA 261 development in the elastase-induced rat model of AAA via inhibition of MMP-9 and NF-kB 
expression.(93) We also recently demonstrated that the rapamycin rapalog everolimus, restricts AAA development in the Ang II-induced $\mathrm{ApoE}^{-/}$mouse model by suppressing the development and migration of bone marrow derived chemokine receptor 2 expressing monocytes.(44) In vitro, we found that everolimus abrogated Ang II-stimulated production of interferon gamma (IFN- $\gamma$ ) in $\mathrm{ApoE}^{-/-}$mice bone marrow. Furthermore, the potent immunosuppressive drugs, methylprednisolone and cyclosporine were demonstrated to inhibit AAA formation in an elastase-induced rat model of AAA.(94) The major difference between the cyclosporine treated and methylprednisolone treated groups was the presence of moderate oedema in the cyclosporine treated animals. However, both groups exhibited intact elastin lamellae.(94) Considering the generalised systemic effects of immune suppressants and the difficulty in achieving a balance between the beneficial and the detrimental effects of these medications, it is unclear whether this form of treatment would be appropriate for older patients at risk of cancer and serious infective complications.

Curcumin (diferuloylmethane), a natural phenol found in the dietary spice tumeric has been reported to exert anti-inflammatory effects via inhibition of the production of ROS and nitric oxide synthase enzymes.(95-97) Preliminary studies by Parodi et al. employing an elastase-induced mouse model of AAA revealed that curcumin decreased aortic tissue concentrations of MCP-1, IL-6, NF- $\kappa$ B, interleukin-1 $\beta$ (IL-1 $\beta$ ) and MMP-9. AAA development in the mice that received oral administration of curcumin was reduced.(98) Given the potential carcinogenic effects ascribed to cucurmin,(99) caution is advised in furthering this agent as a potential therapy for AAA. Examples of animal and human association studies investigating the therapeutic effect of targeting inflammatory pathways are outlined in Table 3.

Statins are a class of lipid-lowering drugs, also known as 3-hydroxyl-3-methylglutaryl coenzyme A (HMG-CoA) reductase inhibitors with putative beneficial pleiotropic effects including antioxidant, anti-inflammatory and anti-proteolytic effects which may be beneficial in various cardiovascular diseases.(100-104) Statins have also been shown to improve stability of atherosclerotic plaque, inhibit thrombogenesis, and improve endothelial function.(105, 106) Despite the lack of convincing association between serum cholesterol and AAA expansion rate, several data indicate that statin therapy may inhibit AAA pathogenesis due to the above-mentioned pleiotropic effects (Table 4).(46, 107-113)

Simvastatin has been reported to inhibit AAA development in a number of rodent studies.(46, 107, 110, 114) For example, Steinmetz et al. demonstrated that simvastatin inhibited AAA formation independent of serum cholesterol levels in the C57BL/6 wildtype and in hyperlipidaemic $\mathrm{ApoE}^{-/}$mice using the elastase-infused mice model of AAA.(107) The authors showed a reduction in MMP-9 expression with a marked increase in tissue inhibitor of metalloproteinase-1 (TIMP-1) expression, maintenance of elastin integrity, and VSMC preservation but no effect on inflammatory infiltrate 
composition following administration of simvastatin.(107) In support, Kalyanasundaram et al. showed that simvastatin inhibited AAA formation in an elastase-induced rat model.(110) They also demonstrated that simvastatin reduced NF- $\mathrm{kB}$ and MMP-9 concentrations, and further downregulated the gene expression of several proinflammatory cytokines and chemokines.(110) In contrast, in a further study employing the Ang II-induced mouse model of AAA, there was no significant reduction in AAA diameter following simvastatin administration.(46) Interestingly simvastatin exerted a more potent effect on intimal atherosclerosis rather than on aortic dilation.(46)

Cerivastatin a synthetic statin withdrawn from the general circulation in 2001 (due to reports of fatal rhabdomyolysis),(115) has been reported to decrease MMP-9 concentration and neutrophil activation with no effect on TIMP-1 in ex vivo human AAA organ culture.(116) Furthermore, inhibition of cerivastatin activity abrogated these effects on proteolysis and inflammation.

Atorvastatin has been reported to prevent AAA development by suppressing macrophage recruitment via inhibition of MCP-1, MMP-12 and ICAM-1 but not MMP-9 expression in an elastase-induced rat model of AAA.(113) In a similar experiment, Houdek and colleagues did not find any significant reduction in AAA formation in mice administered atorvastatin.(117) They did report a noticeable improvement in elastin integrity and VSMC preservation in the atorvastatin treated group.(117) Takahashi et al., demonstrated no significant effect of atorvastatin on aortic diameter in an Ang IIinduced mouse model of AAA.(118) They did however show that combined therapy with amlodipine, a calcium channel blocker significantly suppressed aneurysm formation via inhibition of Rho-kinase activity and elastin degradation.(118) Also, we have previously reported that fenofibrate a peroxisome proliferator-activated receptor alpha (PPAR $\alpha$ ) activator used clinically to reduce triglycerides antagonizes Ang II-induced AAA in low-density lipoprotein receptor-deficient $\left(\mathrm{Ldlr}^{-/}\right)$and $\mathrm{ApoE}^{-/-}$ mice. $(48,119)$

Several human observational investigations report an association between statin treatment and reduced AAA progression.(108, 109, 111, 120-123) In a prospective study investigating the beneficial effect of simvastatin in 32 patients, Evans et al., demonstrated a 40\% reduction in MMP-9 levels in the AAA wall in patients randomised to simvastatin compared to placebo prior to open aneurysm repair.(111) Schweitzer and colleagues reported a reduction in MMP-13, transforming growth factor beta (TGF- $\beta$ ), but not MMP-9 in 19 patients administered atorvastatin compared to 19 patients not receiving atorvastatin.(124) Schouten et al. investigated the effect of statins on 150 patients under surveillance for AAA.(108) They demonstrated a significant reduction in AAA growth rate independent of other cardiovascular factors in 59 patients receiving statins compared to 91 patients not on statins, after approximately 3 years median follow-up.(108) In another retrospective study evaluating the effects of statins on the growth rate of small aneurysm in 211 patients, Karrowni and colleagues demonstrated a significant association between statins use and reduced AAA expansion.(122) They showed that the mean growth rate for 75 patients not receiving statins was $3.2 \mathrm{~mm}$ per year but $0.9 \mathrm{~mm}$ per year for 136 
Some larger clinical studies, however have failed to confirm an association of statins with reduced

343 AAA expansion rate. $(125,126)$ For example, in a multicentre large observational study analysing the 344 effects of statins on AAA growth in 652 patients undergoing surveillance of small AAAs, we found no

345 significant association of statins prescription with AAA growth.(126) Patients receiving statins ( $\mathrm{n}=349$ )

346 were compared with patients not prescribed statins ( $\mathrm{n}=303)$. AAA growth were similar in both patient 347 group,(126) which was in contrast to earlier but smaller studies described above.(108, 111, 122, 123)

348 This finding was further reinforced by the Tromso study, in which Forsdahl et al. reported follow up of 3494000 subjects over seven years.(127) They reported that the subjects receiving statins were more likely 350 to develop AAAs. It is possible that statins prescription simply identified a sub-set of individuals with 351 risk factors putting them at excess likelihood of developing an AAA, although the investigators did 352 attempt to adjust for potential confounding factors.(127) A large number of studies have suggested 353 improved perioperative and postoperative longer-term outcomes in patients prescribed statins prior to 354 aneurysm repair.(101, 128-136) Recent European and American guidelines suggest that patients with 355 large AAAs being considered for intervention should receive statins because of considerable data 356 linking statins with reduced cardiovascular events. $(137,138)$ A randomised trial to examine the benefit 357 of statins in reducing AAA expansion would therefore be far more straightforward to undertake.

\subsection{NF-кB, Rho/Rho-kinase and c-Jun N-terminal kinase inhibitors}

360 The pharmacological modulation of signalling pathways including c-Jun N-terminal kinase (JNK), NF$361 \kappa \mathrm{B}$, Rho/Rho-kinase has been suggested as an effective therapy for AAA in rodent studies (Table 362 5).(139-143) Wang et al. reported that Ang II-infused ApoE$^{-/-}$mice given fasudil [5-(1,4-diazepane-1sulfonyl) isoquinoline], a Rho-kinase inhibitor in their drinking water had both a reduced incidence and severity of Ang II-induced AAA. Fasudil was shown to reduce proteolysis by MMP-2 and MMP-9 with consequent decrease in VSMC apoptosis and AAA formation.(143)

In a different group of studies the therapeutic potential of JNK, an important regulator of activator protein 1 (AP-1, which is a key transcriptional regulator of MMP-9), has been described.(139, 141, 144) In calcium chloride-induced and Ang II-induced mouse models of AAA, Yoshimura et al. demonstrated that SP600125 (1,9-pyrazoloanthrone), a specific JNK inhibitor, completely abrogated the development of AAA by decreasing MMP-9 expression, macrophage infiltration and improving elastin integrity. SP600125 was also shown to reduce AAA size after experimental induction of AAA

373 with improved elastin integrity by upregulating lysyl oxidase and prolyl-4-hydroxylase, enzymes critical for the crosslinking and stable maturation of elastin and collagen.(139) SP600125 was also

375 shown to suppress the secretion of MMP-2 and MMP-9 in the walls of human AAA explants in culture.(141, 145)

378 A number of studies have suggested that medication-targeting NF- $\mathrm{KB}$ may be useful in treating AAA.(142, 143, 146, 147) NF- $\kappa B$ is a well-researched transcription factor that regulates numerous 380 genes implicated in inflammation and immune response.(148-155) A number of proinflammatory 381 cytokines (e.g TNF- $\alpha$, IL-1, IL-6, IL-2), chemokines (e.g. IL-8),(148-150) adhesion molecules (e.g. 
ICAM-1, VCAM-1), (151, 152) and proteolytic enzymes (e.g. MMPs, MMP-1, -2 and -3, -9),(153,

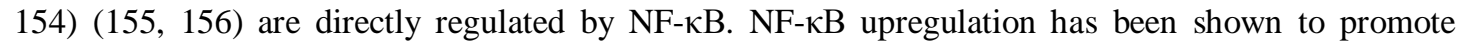
experimental AAA in rats.(146) A recent study in an elastase-induced mouse model of AAA suggested that blocking NF-אB activity with pyrrolidine dithiocarbamate (PDTC) significantly reduced the incidence of AAA and AAA size via inhibition of IL-1 $\beta$, IL-6 and MMP-9 expression.(142)

\subsection{Protease inhibitors}

AAA pathogenesis including formation, growth and eventual rupture is intricately linked with connective tissue destruction especially loss of aortic media and adventitia elastin.(157-161) Proteolytic enzymes such as MMP-9 and -2 have been implicated in ECM degradation resulting in aneurysm formation.(144, 162, 163) Animal based investigations,(164) as well as in vitro studies on human aortic tissue $(157,160)$ suggest that proteases including MMPs, cathepsins, and neutrophil elastase secreted by inflammatory cells and VSMC are involved in the destruction of the aortic wall and subsequent AAA formation.(157-160) MMPs are $\mathrm{Zn}^{2+}$ and $\mathrm{Ca}^{2+}$ dependent enzymes,(158, 165, 166) and are secreted in an inactive zymogen form.(157) They are then activated by mast cells and plasmin generated from plasminogen by the action of plasminogen activating factors such as urokinasetype plasminogen activator (uPA) and tissue plasminogen activator (tPA). Physiologically, MMP activity is strictly regulated by inhibitors such as $\alpha 2$-macroglobullins, $\alpha 1$-antitrypsin and TIMP, which help to control the connective tissue turnover rate. However, aberrant protease expression can result in unbalanced MMP activity, and lead to pathological destruction of the aortic media.(157, 167, 168) MMP-9 (gelatinase B), and MMP-12 (macrophage elastase) are elevated in animal models of AAA as well as plasma and sera from patients with AAA.(168, 169) MMP-3 (Stromelysin-1) and MMP-7 (matrilysin) are also reported to be increased in aneurysmal tissue.(160) Over expression of the collagenases MMP-1 (interstitial collagenase) and MMP-13 (collagenase 3) results in interstitial collagen degradation and promotes AAA formation. Additionally, high levels of MMP-2 (gelatinase A), are found in small AAAs, which suggests a role for MMP-2 in early aneurysm formation.(170)

The theory that Chlamydia or similar infections was important in AAA pathogenesis initially drove an 411 blocking the active form of MMP-2 and -9 with the tetracycline derivative, doxycycline suppressed 412 AAA formation in an elastase-induced rat model of AAA.(172) Kaito and colleagues demonstrated in a 413 similar model that doxycycline inhibited MMP-9 activity with consequent decrease in AAA 414 development without affecting MMP-2 activity.(173) Accumulated evidence derived from in vitro, in 415 vivo and human studies suggested that doxycycline preserved aortic elastin integrity in a dose 416 dependent manner, reduced MMP-9 activity and AAA growth with no effect on MMP-14, -2 and TIMP expression.(157, 162, 173-182)

419 A study by Franklin et al. suggested that patients who received a bolus of tetracycline prior to elective 420 aneurysm repair surgery had reduced MMP-9 and MCP-1 expression.(181) In another study, 
preoperative administration of doxycycline was shown to decrease MMP-9 expression and increase abrogation of pro-MMP-2 activation in the aortic wall.(183) Mosorin et al. initially published a randomised placebo-controlled trial of doxycycline in 32 patients with small AAAs measuring between 30 and $55 \mathrm{~mm}$.(184) They reported that doxycycline decreased AAA expansion rate in patients administered doxycycline compared to patients receiving placebo but the difference was not statistically significant.(184) In a double-blind randomised Phase II clinical trial of 36 patients with small AAAs, doxycycline was shown to be safe and well tolerated and associated with significant decrease in plasma MMP-9 levels with no significant effect on AAA expansion.(185) Linderman et al., reported that doxycycline reduced inflammation in AAA biopsies compared to placebo in a randomised trial of patients undergoing open AAA repair.(186) In a separate randomised trial in patients after endovascular AAA repair, Hackmann and colleagues found that doxycycline reduced plasma levels of MMP-9, which has been suggested as a biomarker of endograft failure.(187) Meijer et al. published the results of a large multicentre randomised, placebo-controlled, double-blind trial investigating the effect of doxycycline on 286 patients with small AAAs (mean aortic diameter 43mm) completed in the Netherlands recently.(188) They reported that doxycycline administration was associated with increased AAA growth [4.1 mm, $(n=144)$ ] compared to the placebo allocated group [3.3 mm, $(n=142)$ ] after 18 months.(188) Another doxycycline trial is currently ongoing in the USA. Other strategies of modifying aortic ECM remodeling are also been explored. For example, Allaire et al. demonstrated that overexpression of TIMP-1 in VSMC significantly reduced AAA development in a rat model of AAA.(72) Despite encouraging data from pre-clinical studies, targeting ECM proteolysis has as yet not translated into a clinically useful strategy. Examples of animal and human studies examining the effect of protease inhibitors on AAA are shown in Table 5.

\subsection{Immune cell modulators}

446 A defining feature of AAA is inflammation including an extensive infiltration of mononuclear 447 lymphocytes and macrophages in the AAA wall.(16, 17, 189) It is proposed that these cells release a 448 cascade of cytokines that activate proteases and thereby degrade the vessel wall. The stimuli that 449 initiate inflammation in human AAA still remain to be elucidated. Experimental evidence suggests that elastin and collagen degradation products in the aortic wall promote the recruitment of inflammatory cells.(17, 190, 191) The marked inflammation and the identification of IgG in AAA tissue which is reactive to ECM proteins supports the concept that AAA development is an autoimmune response.(192) A genetic investigation suggested an association between a human leukocyte antigen

454 (HLA) allele and AAA (HLA-DQA1).(193) Both innate (natural killer/NK cells, mast cells) and adaptive (cytotoxic lymphocytes) immune effectors are elevated in the circulation of patients with AAA.(194-197) Helper T-cell type-1 (Th1) and type-2 (Th2) cytokines have been identified in both human AAA and animal models.(198) Proinflammatory molecules such as IL-6, IFN- $\gamma$, TNF- $\alpha$, IL-8 and MCP-1 have been reported to be upregulated in AAA tissue and to be responsible for ECM remodelling.(17, 199, 200) Suppression of AAA development has been reported to be associated with the inhibition of inflammatory cells in rodent models.(196, 201, 202) 

biopsies, and mast cell deficient mice were shown to be resistant to experimental AAA.(196, 203) In both an elastase-induced and calcium chloride-induced mouse models of AAA, disodium cromoglycate (DSCG), a mast cell stabilizer was shown to significantly inhibit AAA growth by maintaining elastin architecture and decreasing inflammation whilst C48/80 a mast cell activator was shown to increase AAA growth.(196) The authors also demonstrated that mast cell deficient mice failed to develop elastase or calcium chloride induced AAA.(196) Similarly, Tsuruda et al. found that tranilast, a mast cell degranulation inhibitor attenuated AAA development in rodents.(202) There is considerable interest in employing mast cell stabilising agents as a therapy for patients with small aneurysms,(53) and a current randomised trial is examining this approach.

\subsection{Anti-platelet therapy}

Most AAAs contain intraluminal thrombus and we had previously reported a close correlation between thrombus volume and AAA diameter.(204) It has been demonstrated that AAA thrombus is a rich source of inflammatory cells, proteolytic enzymes and proinflammatory cytokines.(40,73, 205) We have also demonstrated that circulating levels of thrombus products are significantly associated with AAA presence and progression in patients with small AAAs.(206, 207)

Platelet inhibition has been reported to inhibit AAA formation in rodent models.(205, 208) Tout et al. demonstrated that abciximab, a platelet aggregation inhibitor reduced both thrombus area and aneurysmal enlargement in a rat model of AAA.(205) In a similar study, another platelet aggregation inhibitor, ticagrelor (AZD6140) was shown to reduce elastin degradation and suppress AAA growth.(208)

Two association studies have suggested the efficacy of anti-platelet medication in limiting AAA progression.(209, 210) Karlsson and colleagues reported that the anti-platelet medication, aspirin (acetylsalicylic acid) was associated with reduced AAA expansion.(209) They also reported that a combination of aspirin and statins therapy was more powerfully associated with limited AAA expansion than aspirin or statins alone.(209) In a different study, Lindholt et al. reported that aspirin prescription was associated with reduced progression of small AAAs.(210) However, more recent and larger studies have failed to demonstrate any strong association between anti-platelet medication and AAA expansion. $(64,125,126)$

\section{Conclusion and future directions}

495 Animal and human data suggests that a complex group of mechanisms are involved in AAA 496 pathogeneses. The last couple of decades have seen a massive increase in research assessing potential 497 pharmacotherapy for AAA in experimental models. Several agents targeting mechanisms implicated in 498 AAA pathogenesis including the RAS, proteolytic processes, inflammatory pathways, the immune 
system and intracellular signalling pathways, have been reported to be effective in pre-clinical studies. It should be noted that the therapeutic manipulation of microRNAs and their target genes have also

501 been shown to limit experimental AAA progression recently. $(211,212)$ However, the efficacy of these

502 agents has not currently been confirmed in large clinical trials. For example, the efficacy of the very 503 promising tetracycline derivative, doxycycline reported to inhibit AAA progression in many rodent 504 pre-clinical and clinical studies, has recently come into doubt with the report of no benefit in a large 505 randomised clinical trial.(188) The difficulty in translating results from animal studies to patients is 506 likely due to a number of factors. Firstly investigating drug therapy targets in patients with AAA is 507 complex. These patients are mainly older adults that frequently have co-morbidities, including 508 coronary heart disease and cancer, precluding the use of medications that may have significant toxic 509 side effects. Given the co-morbidities of AAA patients, they are often receiving a range of medications 510 for other indications, which also makes it difficult to effectively test some medications in trials such as 511 statins, which are already indicated for cardiovascular risk reduction. Secondly the current major 512 animal models of AAA rely on acute injury to the aortic wall and it remains unclear how well these 513 models are suited to identifying treatment targets for human AAA. Thirdly the development of targeted 514 drugs for any medical condition can take a prolonged time and requires significant investment 515 particularly from pharmaceutical companies. Only recently have drug companies become interested in 516 this area and therefore a lag in the development of medications is expected. It is also possible due to 517 the multifactorial nature of AAA that a successful drug will have to target multiple pathways. There are 518 a growing number of trials of medications in AAA patients and therefore it is expected that one or more 519 effective medications will be identified in the near future. It is possible that better delivery of 520 therapeutic agents,(213-215) and a means of monitoring the efficiency of these agents on AAA 521 progression in blood (e.g. using biomarkers),(216) may help identify effective medications for AAA 522 patients. Whether the use of animal models is an effective means to identify appropriate agents to limit 523 AAA progression remains to be proven. 
535 Abdominal aortic aneurysm (AAA), extracellular matrix (ECM), matrix metalloproteinases (MMPs), 536 vascular smooth muscles (VSMC), Intraluminal thrombus (ILT), Neutrophil gelatinase associated 537 lipocalin (NGAL), renin angiotensin system (RAS), angiotensin II (Ang II), angiotensin converting 538 enzyme (ACE), Ang II receptor blockers (ARB), apolipoprotein E deficient (ApoE ${ }^{-/}$), nuclear factor$\kappa \mathrm{B}(\mathrm{NF}-\mathrm{\kappa B})$, monocyte chemoattractant protein-1 (MCP-1), tumor necrosis factor- $\alpha$ (TNF- $\alpha$ ), reactive oxygen species (ROS), interleukin-6 (IL-6), prostaglandin E2 ( $\left.\mathrm{PGE}_{2}\right)$, cyclooxygenase e.g

541 cyclooxygenase-2 (COX-2), nonsteroidal anti-inflammatory drug (NSAID), vascular cell adhesion molecule-1 (VCAM-1), intercellular adhesion molecule-1 (ICAM-1), interferon gamma (IFN- $\gamma$,

543 interleukin-1 $\beta$ (IL-1 $\beta$ ), 3-hydroxyl-3-methylglutaryl coenzyme A (HMG-CoA), tissue inhibitor of 544 metalloproteinase-1 (TIMP-1, c-Jun N-terminal kinase (JNK), peroxisome proliferator-activated receptor alpha (PPAR $\alpha$ ), transforming growth factor beta (TGF- $\beta$ ), pyrollidine dithiocarbamate (PDTC), human leukocyte antigen (HLA), urokinase-type plasminogen activator (uPA), tissue plasminogen activator (tPA), helper T-cell (Th), and disodium cromoglycate (DSCG).

\section{Conflict of interest}

None Declared

\section{Funding}

555 Research undertaken by J.G is supported by the National Health and Medical Research Council (project grant numbers 1063476, 1022752, 1021416, 1020955, 1003707; Practitioner Fellowship

557 number 1019921; and a Centre of Research Excellence number 1000967), the Queensland Government 558 and The Townsville Hospital Private Practice Trust Fund. SWS is supported by the National Heart 559 Foundation (NHF) of Australia Fellowship (PF12B6825). The funding bodies played no role in the 560 production of this paper. 


\section{References}

569 1. Emeto TI, Moxon JV, Biros E, Rush CM, Clancy P, Woodward L, et al. Urocortin 2 is

570 associated with abdominal aortic aneurysm and mediates anti-proliferative effects on vascular smooth

571 muscle cells via corticotrophin releasing factor receptor 2. Clinical science (London, England : 1979).

572 2014;126(7):517-27.

5732 2. Lederle FA, Johnson GR, Wilson SE, Chute EP, Littooy FN, Bandyk D, et al. Prevalence and

574 associations of abdominal aortic aneurysm detected through screening. Aneurysm Detection and

575 Management (ADAM) Veterans Affairs Cooperative Study Group. Annals of Internal Medicine.

576 1997;126(6):441-9.

577 3. Sakalihasan N, Limet R, Defawe OD. Abdominal aortic aneurysm. Lancet. 2005;365:1577-89.

578 4. Thompson MM. Controlling the expansion of abdominal aortic aneurysms. British Journal of

579 Surgery. 2003;98(8):897-8.

$580 \quad 5 . \quad$ Moxon JV, Parr A, Emeto TI, Walker P, Norman PE, Golledge J. Diagnosis and monitoring of

581 abdominal aortic aneurysm: current status and future prospects. Current problems in cardiology.

582 2010;35(10):512-48.

583 6. Participants UKSAT. Long-term outcomes of immediate repair compared with surveillance of 584 small abdominal aortic aneurysms. New England Journal of Medicine. 2002;346(19):1445-52.

585 7. Golledge J, Norman PE. Pathophysiology of abdominal aortic aneurysm relevant to

586 improvements in patients' management. Current Opinion in Cardiology. 2009; In press.

587 8. Hughes ML, Fontenelle LJ. A 5-year review of abdominal aortic aneurysms at a VA medical

588 center. Current Surgery. 2000;57(4):343-5.

589 9. Rooke TW, Hirsch AT, Misra S, Sidawy AN, Beckman JA, Findeiss LK, et al. 2011

590 ACCF/AHA Focused Update of the Guideline for the Management of Patients With Peripheral Artery

591 Disease (updating the 2005 guideline): a report of the American College of Cardiology

592 Foundation/American Heart Association Task Force on Practice Guidelines. Journal of the American

593 College of Cardiology. 2011;58(19):2020-45.

594 10. Timaran CH, Veith FJ, Rosero EB, Modrall JG, Arko FR, Clagett GP, et al. Endovascular

595 aortic aneurysm repair in patients with the highest risk and in-hospital mortality in the United States.

596 Archives of Surgery. 2007;142(6):520-4.

597 11. Brox AC, Filion KB, Zhang X, Pilote M, Obrand D, Haider S, et al. In-hospital cost of

598 abdominal aortic aneurysm repair in Canada and the United States. Archives of Internal Medicine.

599 2003;163:2500-4.

600 12. Gandhi RH, Irizarry E, Cantor JO, Keller S, Nackman GB, Halpern VJ, et al. Analysis of

601 elastin cross-linking and the connective tissue matrix of abdominal aortic aneurysms. Surgery.

602 1994;115(5):617-20.

603 13. Lopez-Candales A, Holmes DR, Liao S, Scott MJ, Wickline SA, Thompson RW. Decreased

604 vascular smooth muscle cell density in medial degeneration of human abdominal aortic aneurysms. The

605 American journal of pathology. 1997;150(3):993-1007. 

smooth muscle cell density in medial degeneration of human abdominal aortic aneurysms. The American journal of pathology. 1997;150(3):993-1007. smooth muscle cell apoptosis in aneurysmal, occlusive, and normal human aortas. Journal of vascular surgery. 2000;31(3):567-76.

612 16. Koch AE, Haines GK, Rizzo RJ, Radosevich JA, Pope RM, Robinson PG, et al. Human abdominal aortic aneurysms. Immunophenotypic analysis suggesting an immune-mediated response.

614 The American journal of pathology. 1990;137(5):1199-213.

615 17. Koch A, Kunkel S, Pearce W, Shah M, Parikh D, Evanoff H, et al. Enhanced production of

616 the chemotactic cytokines interleukin-8 and monocyte chemoattractant protein-1 in human abdominal

617 aortic aneurysms. The American journal of pathology. 1993;142(5):1423-31.

618 18. Kazi M, Thyberg J, Religa P, Roy J, Eriksson P, Hedin U, et al. Influence of intraluminal

619 thrombus on structural and cellular composition of abdominal aortic aneurysm wall. Journal of vascular

620 surgery. 2003;38(6):1283-92.

621 19. Gillum RF. Epidemiology of aortic aneurysm in the United States. Journal of Clinical

622 Epidemiology. 1995;48(11):1289-98.

623 20. Sakalihasan N, Limet R, Defawe OD. Abdominal aortic aneurysm. The Lancet.

624 2005;365(9470):1577-89.

625 21. Thompson MM. Controlling the expansion of abdominal aortic aneurysms. British Journal of 626 Surgery. 2003;90(8):897-8.

627 22. Carrell TW, Burnand KG, Booth NA, Humphries J, Smith A. Intraluminal thrombus enhances 628 proteolysis in abdominal aortic aneurysms. Vascular. 2006;14(1):9-16.

629 23. Allison MA, Kwan K, DiTomasso D, Wright CM, Criqui MH. The epidemiology of

630 abdominal aortic diameter. Journal of vascular surgery. 2008;48(1):121-7.

63124 Lindholt JS. Aneurysmal wall calcification predicts natural history of small abdominal aortic 632 aneurysms. Atherosclerosis. 2008;197(2):673-8.

633 25. Parr A, McLaughlin S, McLaughlin M, Golledge J. Aortic calcification and abdominal aortic aneurysm expansion. Atherosclerosis. 2009;202(2):350.

635 26. Vega de Céniga M, Gómez R, Estallo L, de la Fuente N, Viviens B, Barba A. Analysis of

636 Expansion Patterns in 4-4.9 cm Abdominal Aortic Aneurysms. Annals of vascular surgery.

637 2008;22(1):37-44.

638 27. Wolf YG, Thomas WS, Brennan FJ, Goff WG, Sise MJ, Bernstein EF. Computed tomography 639 scanning findings associated with rapid expansion of abdominal aortic aneurysms. Journal of vascular 640 surgery. 1994;20(4):529-35; discussion 35-8.

$64128 . \quad$ Satta J, Laara E, Juvonen T. Intraluminal thrombus predicts rupture of an abdominal aortic 642 aneurysm. Journal of vascular surgery. 1996;23(4):737-9.

643 29. Hans SS, Jareunpoon O, Balasubramaniam M, Zelenock GB. Size and location of thrombus in 644 intact and ruptured abdominal aortic aneurysms. Journal of vascular surgery. 2005;41(4):584-8. 
645 30. Swedenborg J, Ericksson P. The Intraluminal Thrombus as a Source of Proteolytic Activity.

646 Annals of the New York Academy of Sciences. 2006;1085(The Abdominal Aortic Aneurysm:

647 Genetics, Pathophysiology, and Molecular Biology):133-8.

648 31. Golledge J, Iyer V, Jenkins J, Bradshaw B, Cronin O, Walker PJ. Thrombus volume is similar

649 in patients with ruptured and intact abdominal aortic aneurysms. Journal of vascular surgery.

650 2014;59(2):315-20.

651 32. Vorp DA, Lee PC, Wang DH, Makaroun MS, Nemoto EM, Ogawa S, et al. Association of

652 intraluminal thrombus in abdominal aortic aneurysm with local hypoxia and wall weakening. Journal

653 of vascular surgery. 2001;34(2):291-9.

654 33. Yan L, Borregaard N, Kjeldsen L, Moses MA. The High Molecular Weight Urinary Matrix

655 Metalloproteinase (MMP) Activity Is a Complex of Gelatinase B/MMP-9 and Neutrophil Gelatinase-

656 associated Lipocalin (NGAL). Modulation of MMP-9 activity by NGAL. J Biol Chem.

657 2001;276(40):37258-65.

658 34. Jagadesham VP, Scott DJ, Carding SR. Abdominal aortic aneurysms: an autoimmune disease?

659 . Trends in Molecular Medicine. 2008;14(12):522-9.

660 35. Gregory AK, Yin NX, Capella J, Xia S, Newman KM, Tilson MD. Features of autoimmunity

661 in the abdominal aortic aneurysm. Archives of Surgery. 1996;131(1):85-8.

662 36. Bergoeing MP, Thompson RW, Curci JA. Pharmacological targets in the treatment of

663 abdominal aortic aneurysms. Expert opinion on therapeutic targets. 2006;10(4):547-59.

664 37. Golledge J, Norman PE. Current status of medical management for abdominal aortic

665 aneurysm. Atherosclerosis. 2011;217(1):57-63.

666 38. Daugherty A, Cassis LA. Mouse models of abdominal aortic aneurysms. Arteriosclerosis,

667 thrombosis, and vascular biology. 2004;24(3):429-34.

668 39. Trollope A, Moxon JV, Moran CS, Golledge J. Animal models of abdominal aortic aneurysm

669 and their role in furthering management of human disease. Cardiovascular pathology : the official

670 journal of the Society for Cardiovascular Pathology. 2011;20(2):114-23.

671 40. Moxon JV, Padula MP, Clancy P, Emeto TI, Herbert BR, Norman PE, et al. Proteomic

672 analysis of intra-arterial thrombus secretions reveals a negative association of clusterin and

673 thrombospondin-1 with abdominal aortic aneurysm. Atherosclerosis. 2011;219(2):432-9.

674 41. Moran CS, McCann M, Karan M, Norman P, Ketheesan N, Golledge J. Association of

675 osteoprotegerin with human abdominal aortic aneurysm progression. Circulation. 2005;111(23):3119-

67625.

677 42. Golledge J, Clancy P, Moran C, Biros E, Rush C, Walker P, et al. The novel association of the

678 chemokine CCL22 with abdominal aortic aneurysm. The American journal of pathology.

679 2010;176(5):2098-106.

680 43. Seto SW, Krishna SM, Moran CS, Liu D, Golledge J. Aliskiren limits abdominal aortic

681 aneurysm, ventricular hypertrophy and atherosclerosis in an apolipoprotein E deficient mouse model.

682 Clinical science (London, England : 1979). 2014. 

aortic aneurysm in the apolipoprotein E-deficient mouse by downregulating C-C chemokine receptor 2 positive monocytes. Arteriosclerosis, thrombosis, and vascular biology. 2013;33(4):814-21. 45. King VL, Trivedi DB, Gitlin JM, Loftin CD. Selective cyclooxygenase-2 inhibition with celecoxib decreases angiotensin II-induced abdominal aortic aneurysm formation in mice.

688 Arteriosclerosis, thrombosis, and vascular biology. 2006;26(5):1137-43. 46. Golledge J, Cullen B, Moran C, Rush C. Efficacy of simvastatin in reducing aortic dilatation in mouse models of abdominal aortic aneurysm. Cardiovascular drugs and therapy / sponsored by the International Society of Cardiovascular Pharmacotherapy. 2010;24(5-6):373-8. 47. Daugherty A, Rateri DL, Cassis LA. Role of the renin-angiotensin system in the development of abdominal aortic aneurysms in animals and humans. Annals of the New York Academy of Sciences. 2006;1085:82-91. 48. Golledge J, Cullen B, Rush C, Moran CS, Secomb E, Wood F, et al. Peroxisome proliferatoractivated receptor ligands reduce aortic dilatation in a mouse model of aortic aneurysm. Atherosclerosis. 2010;210(1):51-6. 49. Golledge J. Is there a new target in the renin-angiotensin system for aortic aneurysm therapy? Arteriosclerosis, thrombosis, and vascular biology. 2013;33(7):1456-7.

700 50. Daugherty A, Manning MW, Cassis LA. Angiotensin II promotes atherosclerotic lesions and aneurysms in apolipoprotein E-deficient mice. The Journal of clinical investigation. 2000;105(11):1605-12. 51. Emeto TI, Moxon JV, Rush C, Woodward L, Golledge J. Relevance of urocortins to cardiovascular disease. Journal of molecular and cellular cardiology. 2011;51(3):299-307. 52. Saraff K, Babamusta F, Cassis LA, Daugherty A. Aortic dissection precedes formation of aneurysms and atherosclerosis in angiotensin II-infused, apolipoprotein E-deficient mice.

707 Arteriosclerosis, thrombosis, and vascular biology. 2003;23(9):1621-6.

708 53. Swedenborg J, Mayranpaa MI, Kovanen PT. Mast cells: important players in the orchestrated 709 pathogenesis of abdominal aortic aneurysms. Arteriosclerosis, thrombosis, and vascular biology.

710 2011;31(4):734-40.

711 54. Railton CJ, Wolpin J, Lam-McCulloch J, Belo SE. Renin-angiotensin blockade is associated

712 with increased mortality after vascular surgery. Canadian journal of anaesthesia = Journal canadien

713 d'anesthesie. 2010;57(8):736-44.

714 55. Tsunemi K, Takai S, Nishimoto M, Yuda A, Hasegawa S, Sawada Y, et al. Possible roles of 715 angiotensin II-forming enzymes, angiotensin converting enzyme and chymase-like enzyme, in the 716 human aneurysmal aorta. Hypertension research : official journal of the Japanese Society of

717 Hypertension. 2002;25(6):817-22.

718 56. Nishimoto M, Takai S, Fukumoto H, Tsunemi K, Yuda A, Sawada Y, et al. Increased local 719 angiotensin II formation in aneurysmal aorta. Life sciences. 2002;71(18):2195-205.

720 57. Chrysant SG. Vascular remodeling: the role of angiotensin-converting enzyme inhibitors.

721 American heart journal. 1998;135(2 Pt 2):S21-30. 

1998;97(14):1411-20.

724 59. Liao S, Miralles M, Kelley BJ, Curci JA, Borhani M, Thompson RW. Suppression of

725 experimental abdominal aortic aneurysms in the rat by treatment with angiotensin-converting enzyme inhibitors. Journal of vascular surgery. 2001;33(5):1057-64.

727 60. Daugherty A, Manning MW, Cassis LA. Antagonism of AT2 receptors augments angiotensin

728 II-induced abdominal aortic aneurysms and atherosclerosis. British journal of pharmacology.

729 2001;134(4):865-70.

730 61. Fujiwara Y, Shiraya S, Miyake T, Yamakawa S, Aoki M, Makino H, et al. Inhibition of

731 experimental abdominal aortic aneurysm in a rat model by the angiotensin receptor blocker valsartan.

732 International journal of molecular medicine. 2008;22(6):703-8.

733 62. Staessen JA, Li Y, Richart T. Oral renin inhibitors. Lancet. 2006;368(9545):1449-56.

734 63. Hackam DG, Thiruchelvam D, Redelmeier DA. Angiotensin-converting enzyme inhibitors

735 and aortic rupture: a population-based case-control study. Lancet. 2006;368(9536):659-65.

736 64. Sweeting MJ, Thompson SG, Brown LC, Greenhalgh RM, Powell JT. Use of angiotensin

737 converting enzyme inhibitors is associated with increased growth rate of abdominal aortic aneurysms.

738 Journal of vascular surgery. 2010;52(1):1-4.

739 65. Lederle FA. Should abdominal aortic aneurysm be managed differently in women?

740 Scandinavian journal of surgery : SJS : official organ for the Finnish Surgical Society and the

741 Scandinavian Surgical Society. 2008;97(2):125-7.

742 66. Lederle FA, Johnson GR, Wilson SE. Abdominal aortic aneurysm in women. Journal of

743 vascular surgery. 2001;34(1):122-6.

744 67. Mikkola TS, Clarkson TB. Estrogen replacement therapy, atherosclerosis, and vascular

745 function. Cardiovascular research. 2002;53(3):605-19.

746 68. Ailawadi G, Eliason JL, Roelofs KJ, Sinha I, Hannawa KK, Kaldjian EP, et al. Gender

747 differences in experimental aortic aneurysm formation. Arteriosclerosis, thrombosis, and vascular

748 biology. 2004;24(11):2116-22.

749 69. Martin-McNulty B, Tham DM, da Cunha V, Ho JJ, Wilson DW, Rutledge JC, et al. 17 Beta-

750 estradiol attenuates development of angiotensin II-induced aortic abdominal aneurysm in

751 apolipoprotein E-deficient mice. Arteriosclerosis, thrombosis, and vascular biology. 2003;23(9):1627-

75232.

753 70. Grigoryants V, Hannawa KK, Pearce CG, Sinha I, Roelofs KJ, Ailawadi G, et al. Tamoxifen

754 up-regulates catalase production, inhibits vessel wall neutrophil infiltration, and attenuates

755 development of experimental abdominal aortic aneurysms. Journal of vascular surgery.

756 2005;41(1):108-14.

757 71. Henriques TA, Huang J, D'Souza SS, Daugherty A, Cassis LA. Orchidectomy, but not

758 ovariectomy, regulates angiotensin II-induced vascular diseases in apolipoprotein E-deficient mice.

759 Endocrinology. 2004;145(8):3866-72. 

prevents aortic aneurysm degeneration and rupture in a rat model. The Journal of clinical investigation. 1998;102(7):1413-20.

763 73. Houard X, Touat Z, Ollivier V, Louedec L, Philippe M, Sebbag U, et al. Mediators of neutrophil recruitment in human abdominal aortic aneurysms. Cardiovascular research.

765 2009;82(3):532-41.

766 74. Miller FJ, Jr., Sharp WJ, Fang X, Oberley LW, Oberley TD, Weintraub NL. Oxidative stress in human abdominal aortic aneurysms: a potential mediator of aneurysmal remodeling.

768 Arteriosclerosis, thrombosis, and vascular biology. 2002;22(4):560-5.

769 75. Yajima N, Masuda M, Miyazaki M, Nakajima N, Chien S, Shyy JY. Oxidative stress is 770 involved in the development of experimental abdominal aortic aneurysm: a study of the transcription 771 profile with complementary DNA microarray. Journal of vascular surgery. 2002;36(2):379-85. 76. Ricciotti E, FitzGerald GA. Prostaglandins and Inflammation. Arteriosclerosis, thrombosis,

773 and vascular biology. 2011;31(5):986-1000.

$77477 . \quad$ Miyake T, Morishita R. Pharmacological treatment of abdominal aortic aneurysm.

775 Cardiovascular research. 2009;83(3):436-43.

776 78. Reilly JM, Miralles M, Wester WN, Sicard GA. Differential expression of prostaglandin E2 and interleukin-6 in occlusive and aneurysmal aortic disease. Surgery. 1999;126(4):624-7; discussion 7-8. 79. Bayston T, Ramessur S, Reise J, Jones KG, Powell JT. Prostaglandin E2 receptors in abdominal aortic aneurysm and human aortic smooth muscle cells. Journal of vascular surgery.

2003;38(2):354-9.

782 80. Holmes DR, Wester W, Thompson RW, Reilly JM. Prostaglandin E2 synthesis and cyclooxygenase expression in abdominal aortic aneurysms. Journal of vascular surgery. 1997;25(5):810-5. 81. Walton LJ, Franklin IJ, Bayston T, Brown LC, Greenhalgh RM, Taylor GW, et al. Inhibition of prostaglandin E2 synthesis in abdominal aortic aneurysms: implications for smooth muscle cell viability, inflammatory processes, and the expansion of abdominal aortic aneurysms. Circulation. 1999;100(1):48-54.

789 82. Gitlin JM, Trivedi DB, Langenbach R, Loftin CD. Genetic deficiency of cyclooxygenase-2 attenuates abdominal aortic aneurysm formation in mice. Cardiovascular research. 2007;73(1):227-36.

791 83. Miralles M, Wester W, Sicard GA, Thompson R, Reilly JM. Indomethacin inhibits expansion 792 of experimental aortic aneurysms via inhibition of the cox2 isoform of cyclooxygenase. Journal of vascular surgery. 1999;29(5):884-92; discussion 92-3.

794 84. Holmes DR, Petrinec D, Wester W, Thompson RW, Reilly JM. Indomethacin prevents elastase-induced abdominal aortic aneurysms in the rat. The Journal of surgical research. 1996;63(1):305-9.

797 85. Kearney PM, Baigent C, Godwin J, Halls H, Emberson JR, Patrono C. Do selective cyclooxygenase-2 inhibitors and traditional non-steroidal anti-inflammatory drugs increase the risk of 
atherothrombosis? Meta-analysis of randomised trials. BMJ (Clinical research ed). 2006;332(7553):1302-8.

801 86. Antman EM, Bennett JS, Daugherty A, Furberg C, Roberts H, Taubert KA. Use of

802 nonsteroidal antiinflammatory drugs: an update for clinicians: a scientific statement from the American 803 Heart Association. Circulation. 2007;115(12):1634-42.

804 87. Singh U, Devaraj S, Jialal I. Vitamin E, oxidative stress, and inflammation. Annual review of 805 nutrition. 2005;25:151-74.

806 88. Nakahashi TK, Hoshina K, Tsao PS, Sho E, Sho M, Karwowski JK, et al. Flow loading

807 induces macrophage antioxidative gene expression in experimental aneurysms. Arteriosclerosis,

808 thrombosis, and vascular biology. 2002;22(12):2017-22.

809 89. Gavrila D, Li WG, McCormick ML, Thomas M, Daugherty A, Cassis LA, et al. Vitamin E

810 inhibits abdominal aortic aneurysm formation in angiotensin II-infused apolipoprotein E-deficient

811 mice. Arteriosclerosis, thrombosis, and vascular biology. 2005;25(8):1671-7.

812 90. Tornwall ME, Virtamo J, Haukka JK, Albanes D, Huttunen JK. Alpha-tocopherol (vitamin E)

813 and beta-carotene supplementation does not affect the risk for large abdominal aortic aneurysm in a

814 controlled trial. Atherosclerosis. 2001;157(1):167-73.

815 91. Woods TC, Marks AR. Drug-eluting stents. Annual review of medicine. 2004;55:169-78.

816 92. Kirsch AH, Riegelbauer V, Tagwerker A, Rudnicki M, Rosenkranz AR, Eller K. The mTOR-

817 inhibitor rapamycin mediates proteinuria in nephrotoxic serum nephritis by activating the innate

818 immune response. American journal of physiology Renal physiology. 2012;303(4):F569-75.

819 93. Lawrence DM, Singh RS, Franklin DP, Carey DJ, Elmore JR. Rapamycin suppresses

820 experimental aortic aneurysm growth. Journal of vascular surgery. 2004;40(2):334-8.

821 94. Dobrin PB, Baumgartner N, Anidjar S, Chejfec G, Mrkvicka R. Inflammatory aspects of

822 experimental aneurysms. Effect of methylprednisolone and cyclosporine. Annals of the New York

823 Academy of Sciences. 1996;800:74-88.

824 95. Goel A, Kunnumakkara AB, Aggarwal BB. Curcumin as "Curecumin": from kitchen to clinic.

825 Biochemical pharmacology. 2008;75(4):787-809.

826 96. Chan MM, Huang HI, Fenton MR, Fong D. In vivo inhibition of nitric oxide synthase gene

827 expression by curcumin, a cancer preventive natural product with anti-inflammatory properties.

828 Biochemical pharmacology. 1998;55(12):1955-62.

829 97. Leclercq IA, Farrell GC, Sempoux C, dela Pena A, Horsmans Y. Curcumin inhibits NF-

830 kappaB activation and reduces the severity of experimental steatohepatitis in mice. Journal of

831 hepatology. 2004;41(6):926-34.

832 98. Parodi FE, Mao D, Ennis TL, Pagano MB, Thompson RW. Oral administration of

833 diferuloylmethane (curcumin) suppresses proinflammatory cytokines and destructive connective tissue

834 remodeling in experimental abdominal aortic aneurysms. Annals of vascular surgery. 2006;20(3):360-

8358.

836 99. Burgos-Moron E, Calderon-Montano JM, Salvador J, Robles A, Lopez-Lazaro M. The dark

837 side of curcumin. International journal of cancer Journal international du cancer. 2010;126(7):1771-5. 
100. Liao JK. Clinical implications for statin pleiotropy. Current opinion in lipidology. 2005;16(6):624-9.

840 101. Nomura S, Yoshimura K, Akiyama N, Mikamo A, Furutani A, Aoki H, et al. HMG-CoA

841 reductase inhibitors reduce matrix metalloproteinase-9 activity in human varicose veins. European

842 surgical research Europaische chirurgische Forschung Recherches chirurgicales europeennes.

843 2005;37(6):370-8.

844 102. Rikitake Y, Liao JK. Rho GTPases, statins, and nitric oxide. Circulation research.

845 2005;97(12):1232-5.

846 103. Schonbeck U, Libby P. Inflammation, immunity, and HMG-CoA reductase inhibitors: statins

847 as antiinflammatory agents? Circulation. 2004;109(21 Suppl 1):Ii18-26.

848 104. Takemoto M, Liao JK. Pleiotropic effects of 3-hydroxy-3-methylglutaryl coenzyme a

849 reductase inhibitors. Arteriosclerosis, thrombosis, and vascular biology. 2001;21(11):1712-9.

850 105. Nicholls SJ, Cutri B, Worthley SG, Kee P, Rye KA, Bao S, et al. Impact of short-term

851 administration of high-density lipoproteins and atorvastatin on atherosclerosis in rabbits.

852 Arteriosclerosis, thrombosis, and vascular biology. 2005;25(11):2416-21.

853 106. Hartung D, Sarai M, Petrov A, Kolodgie F, Narula N, Verjans J, et al. Resolution of apoptosis

854 in atherosclerotic plaque by dietary modification and statin therapy. Journal of nuclear medicine :

855 official publication, Society of Nuclear Medicine. 2005;46(12):2051-6.

856 107. Steinmetz EF, Buckley C, Shames ML, Ennis TL, Vanvickle-Chavez SJ, Mao D, et al.

857 Treatment with simvastatin suppresses the development of experimental abdominal aortic aneurysms in 858 normal and hypercholesterolemic mice. Annals of surgery. 2005;241(1):92-101.

859 108. Schouten O, van Laanen JH, Boersma E, Vidakovic R, Feringa HH, Dunkelgrun M, et al.

860 Statins are associated with a reduced infrarenal abdominal aortic aneurysm growth. European journal

861 of vascular and endovascular surgery : the official journal of the European Society for Vascular

862 Surgery. 2006;32(1):21-6.

863 109. Sukhija R, Aronow WS, Sandhu R, Kakar P, Babu S. Mortality and size of abdominal aortic

864 aneurysm at long-term follow-up of patients not treated surgically and treated with and without statins.

865 The American journal of cardiology. 2006;97(2):279-80.

866 110. Kalyanasundaram A, Elmore JR, Manazer JR, Golden A, Franklin DP, Galt SW, et al.

867 Simvastatin suppresses experimental aortic aneurysm expansion. Journal of vascular surgery.

868 2006;43(1):117-24.

869 111. Evans J, Powell JT, Schwalbe E, Loftus IM, Thompson MM. Simvastatin attenuates the

870 activity of matrix metalloprotease-9 in aneurysmal aortic tissue. European journal of vascular and

871 endovascular surgery : the official journal of the European Society for Vascular Surgery.

872 2007;34(3):302-3.

873 112. Zhang Y, Naggar JC, Welzig CM, Beasley D, Moulton KS, Park HJ, et al. Simvastatin

874 inhibits angiotensin II-induced abdominal aortic aneurysm formation in apolipoprotein E-knockout

875 mice: possible role of ERK. Arteriosclerosis, thrombosis, and vascular biology. 2009;29(11):1764-71. 

development of experimental aortic abdominal aneurysm in rat model by atorvastatin through inhibition of macrophage migration. Atherosclerosis. 2009;202(1):34-40. atherosclerotic effect of simvastatin depends on the presence of apolipoprotein E. Atherosclerosis. 2002;162(1):23-31.

882 115. Furberg CD, Pitt B. Withdrawal of cerivastatin from the world market. Current controlled trials in cardiovascular medicine. 2001;2(5):205-7.

884 116. Nagashima H, Aoka Y, Sakomura Y, Sakuta A, Aomi S, Ishizuka N, et al. A 3-hydroxy-3methylglutaryl coenzyme A reductase inhibitor, cerivastatin, suppresses production of matrix metalloproteinase-9 in human abdominal aortic aneurysm wall. Journal of vascular surgery. 2002;36(1):158-63. histopathological progression of porcine experimental abdominal aortic aneurysm is mitigated by atorvastatin. International angiology : a journal of the International Union of Angiology. 2013;32(3):291-306.

892 118. Takahashi K, Matsumoto Y, Do e Z, Kanazawa M, Satoh K, Shimizu T, et al. Combination 893 therapy with atorvastatin and amlodipine suppresses angiotensin II-induced aortic aneurysm formation. 894 PloS one. 2013;8(8):e72558.

895 119. Krishna SM, Seto SW, Moxon JV, Rush C, Walker PJ, Norman PE, et al. Fenofibrate

896 increases high-density lipoprotein and sphingosine 1 phosphate concentrations limiting abdominal

897 aortic aneurysm progression in a mouse model. The American journal of pathology. 2012;181(2):706-

89818.

899 120. Schlosser FJ, Tangelder MJ, Verhagen HJ, van der Heijden GJ, Muhs BE, van der Graaf Y, et

900 al. Growth predictors and prognosis of small abdominal aortic aneurysms. Journal of vascular surgery.

901 2008;47(6):1127-33.

902 121. Mosorin M, Niemela E, Heikkinen J, Lahtinen J, Tiozzo V, Satta J, et al. The use of statins

903 and fate of small abdominal aortic aneurysms. Interactive cardiovascular and thoracic surgery.

904 2008;7(4):578-81.

905 122. Karrowni W, Dughman S, Hajj GP, Miller FJ, Jr. Statin therapy reduces growth of abdominal 906 aortic aneurysms. Journal of investigative medicine : the official publication of the American

907 Federation for Clinical Research. 2011;59(8):1239-43.

908 123. Kajimoto K, Miyauchi K, Kasai T, Shimada K, Kojima Y, Shimada A, et al. Short-term 20-

909 mg atorvastatin therapy reduces key inflammatory factors including c-Jun N-terminal kinase and

910 dendritic cells and matrix metalloproteinase expression in human abdominal aortic aneurysmal wall.

911 Atherosclerosis. 2009;206(2):505-11.

912 124. Schweitzer M, Mitmaker B, Obrand D, Sheiner N, Abraham C, Dostanic S, et al. Atorvastatin

913 modulates matrix metalloproteinase expression, activity, and signaling in abdominal aortic aneurysms.

914 Vascular and endovascular surgery. 2010;44(2):116-22. 

drug modulation of abdominal aortic aneurysm growth through 25 years of surveillance. Journal of vascular surgery. 2010;52(1):55-61 e2.

918 126. Ferguson CD, Clancy P, Bourke B, Walker PJ, Dear A, Buckenham T, et al. Association of statin prescription with small abdominal aortic aneurysm progression. American heart journal.

920 2010;159(2):307-13.

921 127. Forsdahl SH, Singh K, Solberg S, Jacobsen BK. Risk factors for abdominal aortic aneurysms: a 7-year prospective study: the Tromso Study, 1994-2001. Circulation. 2009;119(16):2202-8.

923 128. Twine CP, Williams IM. Systematic review and meta-analysis of the effects of statin therapy 924 on abdominal aortic aneurysms. The British journal of surgery. 2011;98(3):346-53.

925 129. McNally MM, Agle SC, Parker FM, Bogey WM, Powell CS, Stoner MC. Preoperative statin 926 therapy is associated with improved outcomes and resource utilization in patients undergoing aortic aneurysm repair. Journal of vascular surgery. 2010;51(6):1390-6.

928 130. Feeney JM, Burns K, Staff I, Bai J, Rodrigues N, Fortier J, et al. Prehospital HMG Co-A reductase inhibitor use and reduced mortality in ruptured abdominal aortic aneurysm. Journal of the American College of Surgeons. 2009;209(1):41-6.

931 131. Diehm N, Becker G, Katzen B, Benenati J, Kovacs M, Dick F. Statins are associated with 932 decreased mortality in abdominal, but not in thoracic aortic aneurysm patients undergoing endovascular repair: propensity score-adjusted analysis. VASA Zeitschrift fur Gefasskrankheiten. 2008;37(3):241-9.

934 132. Kertai MD, Boersma E, Westerhout CM, Klein J, van Urk H, Bax JJ, et al. Reprinted article "A combination of statins and beta-blockers is independently associated with a reduction in the

936 incidence of perioperative mortality and nonfatal myocardial infarction in patients undergoing abdominal aortic aneurysm surgery". European journal of vascular and endovascular surgery : the official journal of the European Society for Vascular Surgery. 2011;42 Suppl 1:S96-104. 133. Kertai MD, Boersma E, Westerhout CM, van Domburg R, Klein J, Bax JJ, et al. Association between long-term statin use and mortality after successful abdominal aortic aneurysm surgery. The

941 American journal of medicine. 2004;116(2):96-103.

942 134. Kurzencwyg D, Filion KB, Pilote L, Nault P, Platt RW, Rahme E, et al. Cardiac medical therapy among patients undergoing abdominal aortic aneurysm repair. Annals of vascular surgery.

944 2006;20(5):569-76.

945 135. Leurs LJ, Visser P, Laheij RJ, Buth J, Harris PL, Blankensteijn JD. Statin use is associated

946 with reduced all-cause mortality after endovascular abdominal aortic aneurysm repair. Vascular.

947 2006;14(1):1-8.

948 136. Schouten O, Lever TM, Welten GM, Winkel TA, Dols LF, Bax JJ, et al. Long-term cardiac

949 outcome in high-risk patients undergoing elective endovascular or open infrarenal abdominal aortic

950 aneurysm repair. European journal of vascular and endovascular surgery : the official journal of the 951 European Society for Vascular Surgery. 2008;36(6):646-52.

952 137. Chaikof EL, Brewster DC, Dalman RL, Makaroun MS, Illig KA, Sicard GA, et al. The care of 953 patients with an abdominal aortic aneurysm: the Society for Vascular Surgery practice guidelines.

954 Journal of vascular surgery. 2009;50(4 Suppl):S2-49. 

abdominal aortic aneurysms clinical practice guidelines of the European society for vascular surgery. European journal of vascular and endovascular surgery : the official journal of the European Society for Vascular Surgery. 2011;41 Suppl 1:S1-s58.

139. Yoshimura K, Aoki H, Ikeda Y, Fujii K, Akiyama N, Furutani A, et al. Regression of abdominal aortic aneurysm by inhibition of c-Jun N-terminal kinase. Nature medicine. 2005;11(12):1330-8.

140. Yoshimura K, Aoki H, Ikeda Y, Furutani A, Hamano K, Matsuzaki M. Identification of c-Jun

963 N-terminal kinase as a therapeutic target for abdominal aortic aneurysm. Annals of the New York

964 Academy of Sciences. 2006;1085:403-6.

965 141. Yoshimura K, Aoki H, Ikeda Y, Furutani A, Hamano K, Matsuzaki M. Regression of

966 abdominal aortic aneurysm by inhibition of c-Jun N-terminal kinase in mice. Annals of the New York Academy of Sciences. 2006;1085:74-81.

968 142. Parodi FE, Mao D, Ennis TL, Bartoli MA, Thompson RW. Suppression of experimental

969 abdominal aortic aneurysms in mice by treatment with pyrrolidine dithiocarbamate, an antioxidant inhibitor of nuclear factor-kappaB. Journal of vascular surgery. 2005;41(3):479-89.

971 143. Wang YX, Martin-McNulty B, da Cunha V, Vincelette J, Lu X, Feng Q, et al. Fasudil, a Rho972 kinase inhibitor, attenuates angiotensin II-induced abdominal aortic aneurysm in apolipoprotein E973 deficient mice by inhibiting apoptosis and proteolysis. Circulation. 2005;111(17):2219-26.

974 144. Aoki H, Yoshimura K, Matsuzaki M. Turning back the clock: regression of abdominal aortic 975 aneurysms via pharmacotherapy. Journal of molecular medicine (Berlin, Germany). 2007;85(10):107797688.

977 145. Thompson RW. Aneurysm treatments expand. Nature medicine. 2005;11(12):1279-81.

978 146. Shiraya S, Miwa K, Aoki M, Miyake T, Oishi M, Kataoka K, et al. Hypertension accelerated

979 experimental abdominal aortic aneurysm through upregulation of nuclear factor kappaB and Ets.

980 Hypertension. 2006;48(4):628-36.

981 147. Nakashima H, Aoki M, Miyake T, Kawasaki T, Iwai M, Jo N, et al. Inhibition of experimental 982 abdominal aortic aneurysm in the rat by use of decoy oligodeoxynucleotides suppressing activity of nuclear factor kappaB and ets transcription factors. Circulation. 2004;109(1):132-8.

984 148. Morishita R, Higaki J, Tomita N, Ogihara T. Application of transcription factor "decoy" strategy as means of gene therapy and study of gene expression in cardiovascular disease. Circulation research. 1998;82(10):1023-8.

987 149. Libermann TA, Baltimore D. Activation of interleukin-6 gene expression through the NF-

988 kappa B transcription factor. Molecular and cellular biology. 1990;10(5):2327-34.

989 150. Satriano J, Schlondorff D. Activation and attenuation of transcription factor NF-kB in mouse 990 glomerular mesangial cells in response to tumor necrosis factor-alpha, immunoglobulin G, and 991 adenosine 3':5'-cyclic monophosphate. Evidence for involvement of reactive oxygen species. The 992 Journal of clinical investigation. 1994;94(4):1629-36.

993 151. Weber C, Erl W, Pietsch A, Weber PC. Aspirin inhibits nuclear factor-kappa B mobilization 994 and monocyte adhesion in stimulated human endothelial cells. Circulation. 1995;91(7):1914-7. 

gene by inflammatory cytokines in human endothelial cells. Essential roles of a variant NF-kappa B site and p65 homodimers. The Journal of biological chemistry. 1995;270(2):933-43. metalloproteinase-1 and -3 upregulation in rabbit dermal fibroblasts. Biochemical and biophysical research communications. 1999;264(2):561-7. metalloproteinase 9 expression is induced by Epstein-Barr virus latent membrane protein 1 C-terminal activation regions 1 and 2. Journal of virology. 1999;73(7):5548-55.

155. Kim H, Koh G. Lipopolysaccharide activates matrix metalloproteinase-2 in endothelial cells through an NF-kappaB-dependent pathway. Biochemical and biophysical research communications. 2000;269(2):401-5.

156. Chakraborti S, Mandal M, Das S, Mandal A, Chakraborti T. Regulation of matrix metalloproteinases: an overview. Molecular and cellular biochemistry. 2003;253(1-2):269-85. 157. Davis V, Persidskaia R, Baca-Regen L, Itoh Y, Nagase H, Persidsky Y, et al. Matrix Metalloproteinase-2 Production and Its Binding to the Matrix Are Increased in Abdominal Aortic Aneurysms. Arteriosclerosis, thrombosis, and vascular biology. 1998;18(10):1625-33. 158. Abisi S, Burnand KG, Waltham M, Humphries J, Taylor PR, Smith A. Cysteine protease activity in the wall of abdominal aortic aneurysms. Journal of vascular surgery. 2007;46(6):1260-6. 159. Rizas KD, Ippagunta N, Tilson MD, 3rd. Immune cells and molecular mediators in the pathogenesis of the abdominal aortic aneurysm. Cardiol Rev. 2009;17(5):201-10.

\section{160. Carrell TWG, Burnand KG, Wells GMA, Clements JM, Smith A. Stromelysin-1 (Matrix}

1017 Metalloproteinase-3) and Tissue Inhibitor of Metalloproteinase-3 Are Overexpressed in the Wall of 1018 Abdominal Aortic Aneurysms. Circulation. 2002;105(4):477-82.

1019 161. Davis EC. Stability of elastin in the developing mouse aorta: a quantitative radioautographic study. Histochemistry. 1993;100(1):17-26.

1021 162. Pyo R, Lee JK, Shipley JM, Curci JA, Mao D, Ziporin SJ, et al. Targeted gene disruption of 1022 matrix metalloproteinase-9 (gelatinase B) suppresses development of experimental abdominal aortic aneurysms. The Journal of clinical investigation. 2000;105(11):1641-9.

1024 163. Verma S, Lindsay TF. Regression of aortic aneurysms through pharmacologic therapy? The 1025 New England journal of medicine. 2006;354(19):2067-8.

1026 164. Daugherty A, Cassis L. Mouse models of abdominal aortic aneurysms. Arteriosclerosis, 1027 thrombosis, and vascular biology. 2004;24(3):429 - 34.

1028 165. Dollery CM, McEwan JR, Henney AM. Matrix Metalloproteinases and Cardiovascular

1029 Disease. Circulation research. 1995;77(5):863-8.

1030 166. Axisa B, Loftus IM, Naylor AR, Goodall S, Jones L, Bell PRF, et al. Prospective, 1031 Randomized, Double-Blind Trial Investigating the Effect of Doxycycline on Matrix Metalloproteinase 1032 Expression Within Atherosclerotic Carotid Plaques * Editorial Comment. Stroke. 2002;33(12):2858103364. 
1034 167. McMillan WD, Patterson BK, Keen RR, Shively VP, Cipollone M, Pearce WH. In Situ

1035 Localization and Quantification of mRNA for 92-kD Type IV Collagenase and Its Inhibitor in

1036 Aneurysmal, Occlusive, and Normal Aorta. Arteriosclerosis, thrombosis, and vascular biology.

1037 1995;15(8):1139-44.

1038 168. McMillan WD, Pearce WH. Increased plasma levels of metalloproteinase-9 are associated

1039 with abdominal aortic aneurysms. Journal of vascular surgery. 1999;29(1):122-7; discussion 7-9.

1040 169. McMillan WD, Tamarina NA, Cipollone M, Johnson DA, Parker MA, Pearce WH. Size

1041 Matters : The Relationship Between MMP-9 Expression and Aortic Diameter. Circulation.

1042 1997;96(7):2228-32.

1043 170. Wassef M, Baxter BT, Chisholm RL, Dalman RL, Fillinger MF, Heinecke J, et al.

1044 Pathogenesis of abdominal aortic aneurysms: A multidisciplinary research program supported by the

1045 National Heart, Lung, and Blood Institute. Journal of vascular surgery. 2001;34(4):730-8.

1046 171. Juvonen J, Juvonen T, Laurila A, Alakärppä H, Lounatmaa K, Surcel H-M, et al.

1047 Demonstration of Chlamydia pneumoniae in the walls of abdominal aortic aneurysms. Journal of

1048 vascular surgery. 1997;25(3):499-505.

1049 172. Petrinec D, Liao S, Holmes DR, Reilly JM, Parks WC, Thompson RW. Doxycycline

1050 inhibition of aneurysmal degeneration in an elastase-induced rat model of abdominal aortic aneurysm:

1051 preservation of aortic elastin associated with suppressed production of $92 \mathrm{kD}$ gelatinase. Journal of

1052 vascular surgery. 1996;23(2):336-46.

1053 173. Kaito K, Urayama H, Watanabe G. Doxycycline treatment in a model of early abdominal 1054 aortic aneurysm. Surgery today. 2003;33(6):426-33.

1055 174. Thompson RW, Baxter BT. MMP Inhibition in Abdominal Aortic Aneurysms: Rationale for a

1056 Prospective Randomized Clinical Trial. Annals of the New York Academy of Sciences.

1057 1999;878(Inhibition of matrix metalloproteinases therapeutic applications):159-78.

1058 175. Liu J, Xiong W, Baca-Regen L, Nagase H, Baxter BT. Mechanism of inhibition of matrix

1059 metalloproteinase-2 expression by doxycycline in human aortic smooth muscle cells. Journal of

1060 vascular surgery. 2003;38(6):1376-83.

1061 176. Manning MW, Cassis LA, Daugherty A. Differential effects of doxycycline, a broad-spectrum

1062 matrix metalloproteinase inhibitor, on angiotensin II-induced atherosclerosis and abdominal aortic

1063 aneurysms. Arteriosclerosis, thrombosis, and vascular biology. 2003;23(3):483-8.

1064 177. Curci JA, Petrinec D, Liao S, Golub LM, Thompson RW. Pharmacologic suppression of

1065 experimental abdominal aortic aneurysms: acomparison of doxycycline and four chemically modified

1066 tetracyclines. Journal of vascular surgery. 1998;28(6):1082-93.

1067 178. Huffman MD, Curci JA, Moore G, Kerns DB, Starcher BC, Thompson RW. Functional

1068 importance of connective tissue repair during the development of experimental abdominal aortic

1069 aneurysms. Surgery. 2000;128(3):429-38.

1070 179. Prall AK, Longo GM, Mayhan WG, Waltke EA, Fleckten B, Thompson RW, et al.

1071 Doxycycline in patients with abdominal aortic aneurysms and in mice: comparison of serum levels and

1072 effect on aneurysm growth in mice. Journal of vascular surgery. 2002;35(5):923-9. 
180. Sho E, Chu J, Sho M, Fernandes B, Judd D, Ganesan P, et al. Continuous periaortic infusion improves doxycycline efficacy in experimental aortic aneurysms. Journal of vascular surgery. 2004;39(6):1312-21.

181. Franklin IJ, Harley SL, Greenhalgh RM, Powell JT. Uptake of tetracycline by aortic aneurysm wall and its effect on inflammation and proteolysis. The British journal of surgery. 1999;86(6):771-5. 182. Bartoli MA, Parodi FE, Chu J, Pagano MB, Mao D, Baxter BT, et al. Localized administration of doxycycline suppresses aortic dilatation in an experimental mouse model of abdominal aortic aneurysm. Annals of vascular surgery. 2006;20(2):228-36.

183. Curci JA, Mao D, Bohner DG, Allen BT, Rubin BG, Reilly JM, et al. Preoperative treatment with doxycycline reduces aortic wall expression and activation of matrix metalloproteinases in patients with abdominal aortic aneurysms. Journal of vascular surgery. 2000;31(2):325-42.

184. Mosorin M, Juvonen J, Biancari F, Satta J, Surcel HM, Leinonen M, et al. Use of doxycycline to decrease the growth rate of abdominal aortic aneurysms: a randomized, double-blind, placebocontrolled pilot study. Journal of vascular surgery. 2001;34(4):606-10.

185. Baxter BT, Pearce WH, Waltke EA, Littooy FN, Hallett JW, Jr., Kent KC, et al. Prolonged administration of doxycycline in patients with small asymptomatic abdominal aortic aneurysms: report of a prospective (Phase II) multicenter study. Journal of vascular surgery. 2002;36(1):1-12.

186. Lindeman JH, Abdul-Hussien H, van Bockel JH, Wolterbeek R, Kleemann R. Clinical trial of doxycycline for matrix metalloproteinase-9 inhibition in patients with an abdominal aneurysm: doxycycline selectively depletes aortic wall neutrophils and cytotoxic T cells. Circulation. 2009;119(16):2209-16.

187. Hackmann AE, Rubin BG, Sanchez LA, Geraghty PA, Thompson RW, Curci JA. A randomized, placebo-controlled trial of doxycycline after endoluminal aneurysm repair. Journal of vascular surgery. 2008;48(3):519-26; discussion 26.

188. Meijer CA, Stijnen T, Wasser MN, Hamming JF, van Bockel JH, Lindeman JH. Doxycycline for stabilization of abdominal aortic aneurysms: a randomized trial. Ann Intern Med. 2013;159(12):815-23.

189. Brophy CM, Reilly JM, Smith GJ, Tilson MD. The role of inflammation in nonspecific abdominal aortic aneurysm disease. Annals of vascular surgery. 1991;5(3):229-33.

190. Newman KM, Jean-Claude J, Li H, Ramey WG, Tilson MD. Cytokines that activate proteolysis are increased in abdominal aortic aneurysms. Circulation. 1994;90(5 Pt 2):Ii224-7. 191. Shah PK. Inflammation, Metalloproteinases, and Increased Proteolysis : An Emerging Pathophysiological Paradigm in Aortic Aneurysm. Circulation. 1997;96(7):2115-7.

192. Gregory AK, Yin NX, Capella J, Xia S, Newman KM, Tilson MD. Features of autoimmunity in the abdominal aortic aneurysm. Arch Surg. 1996;131(1):85-8.

193. Ogata T, Gregoire L, Goddard KA, Skunca M, Tromp G, Lancaster WD, et al. Evidence for association between the HLA-DQA locus and abdominal aortic aneurysms in the Belgian population: a case control study. BMC Med Genet. 2006;7:67. 
1111 194. Chan WL, Pejnovic N, Liew TV, Hamilton H. Predominance of Th2 response in human

1112 abdominal aortic aneurysm: Mistaken identity for IL-4-producing NK and NKT cells? Cellular

1113 Immunology. 2005;233(2):109-14.

1114 195. Forester ND, Cruickshank SM, Scott DJA, Carding SR. Increased natural killer cell activity in 1115 patients with an abdominal aortic aneurysm. British Journal of Surgery. 2006;93(1):46-54.

1116 196. Sun J, Sukhova GK, Yang M, Wolters PJ, MacFarlane LA, Libby P, et al. Mast cells modulate 1117 the pathogenesis of elastase-induced abdominal aortic aneurysms in mice. The Journal of clinical 1118 investigation. 2007;117(11):3359-68.

1119 197. Sun J, Zhang J, Lindholt JS, Sukhova GK, Liu J, He A, et al. Critical role of mast cell 1120 chymase in mouse abdominal aortic aneurysm formation. Circulation. 2009;120(11):973-82.

1121 198. Platsoucas CD, Lu S, Nwaneshiudu I, Solomides C, Agelan A, Ntsoula N, et al. Abdominal 1122 Aortic Aneurysm Is a Specific Antigen-Driven T Cell Disease. Annals of the New York Academy of 1123 Sciences. 2006;1085(The Abdominal Aortic Aneurysm: Genetics, Pathophysiology, and Molecular 1124 Biology):224-35.

1125 199. Galle C, Schandene L, Stordeur P, Peignois Y, Ferreira J, Wautrecht JC, et al. Predominance 1126 of type 1 CD4+ T cells in human abdominal aortic aneurysm. Clin Exp Immunol. 2005;142(3):519-27.

1127 200. Treska V, Topolcan O, Pecen L. Cytokines as plasma markers of abdominal aortic aneurysm.

1128 Clinical chemistry and laboratory medicine : CCLM / FESCC. 2000;38(11):1161-4.

1129 201. Pagano MB, Zhou HF, Ennis TL, Wu X, Lambris JD, Atkinson JP, et al. Complement-

1130 dependent neutrophil recruitment is critical for the development of elastase-induced abdominal aortic

1131 aneurysm. Circulation. 2009;119(13):1805-13.

1132 202. Tsuruda T, Kato J, Hatakeyama K, Kojima K, Yano M, Yano Y, et al. Adventitial mast cells 1133 contribute to pathogenesis in the progression of abdominal aortic aneurysm. Circulation research. 1134 2008;102(11):1368-77.

1135 203. Mayranpaa MI, Trosien JA, Fontaine V, Folkesson M, Kazi M, Eriksson P, et al. Mast cells 1136 associate with neovessels in the media and adventitia of abdominal aortic aneurysms. Journal of 1137 vascular surgery. 2009;50(2):388-95; discussion 95-6.

1138 204. Golledge J, Wolanski P, Parr A, Buttner P. Measurement and determinants of infrarenal aortic 1139 thrombus volume. European radiology. 2008;18(9):1987-94.

1140 205. Touat Z, Ollivier V, Dai J, Huisse MG, Bezeaud A, Sebbag U, et al. Renewal of mural 1141 thrombus releases plasma markers and is involved in aortic abdominal aneurysm evolution. The 1142 American journal of pathology. 2006;168(3):1022-30.

1143 206. Golledge J, Tsao PS, Dalman RL, Norman PE. Circulating markers of abdominal aortic 1144 aneurysm presence and progression. Circulation. 2008;118(23):2382-92.

1145 207. Golledge J, Muller R, Clancy P, McCann M, Norman PE. Evaluation of the diagnostic and 1146 prognostic value of plasma D-dimer for abdominal aortic aneurysm. European heart journal. 1147 2011;32(3):354-64.

1148 208. Dai J, Louedec L, Philippe M, Michel JB, Houard X. Effect of blocking platelet activation 1149 with AZD6140 on development of abdominal aortic aneurysm in a rat aneurysmal model. Journal of 1150 vascular surgery. 2009;49(3):719-27. 
1151 209. Karlsson L, Gnarpe J, Bergqvist D, Lindback J, Parsson H. The effect of azithromycin and

1152 Chlamydophilia pneumonia infection on expansion of small abdominal aortic aneurysms--a prospective

1153 randomized double-blind trial. Journal of vascular surgery. 2009;50(1):23-9.

1154 210. Lindholt JS, Sorensen HT, Michel JB, Thomsen HF, Henneberg EW. Low-dose aspirin may

1155 prevent growth and later surgical repair of medium-sized abdominal aortic aneurysms. Vascular and

1156 endovascular surgery. 2008;42(4):329-34.

1157 211. Golledge J, Kuivaniemi H. Genetics of abdominal aortic aneurysm. Curr Opin Cardiol.

1158 2013;28(3):290-6.

1159 212. Maegdefessel L, Azuma J, Toh R, Merk DR, Deng A, Chin JT, et al. Inhibition of microRNA-

$116029 \mathrm{~b}$ reduces murine abdominal aortic aneurysm development. The Journal of clinical investigation.

1161 2012;122(2):497-506.

1162 213. Deux JF, Dai J, Riviere C, Gazeau F, Meric P, Gillet B, et al. Aortic aneurysms in a rat model:

1163 in vivo MR imaging of endovascular cell therapy. Radiology. 2008;246(1):185-92.

1164 214. Broz P, Ben-Haim N, Grzelakowski M, Marsch S, Meier W, Hunziker P. Inhibition of

1165 macrophage phagocytotic activity by a receptor-targeted polymer vesicle-based drug delivery

1166 formulation of pravastatin. Journal of cardiovascular pharmacology. 2008;51(3):246-52.

1167 215. Banciu M, Metselaar JM, Schiffelers RM, Storm G. Antitumor activity of liposomal

1168 prednisolone phosphate depends on the presence of functional tumor-associated macrophages in tumor

1169 tissue. Neoplasia (New York, NY). 2008;10(2):108-17.

1170 216. Golledge J, Powell JT. Medical management of abdominal aortic aneurysm. European journal

1171 of vascular and endovascular surgery : the official journal of the European Society for Vascular

1172 Surgery. 2007;34(3):267-73.

1173

1174

1175

1176

1177

1178

1179

1180

1181

1182

1183

1184

1185

1186

1187

1188

1189

1190 


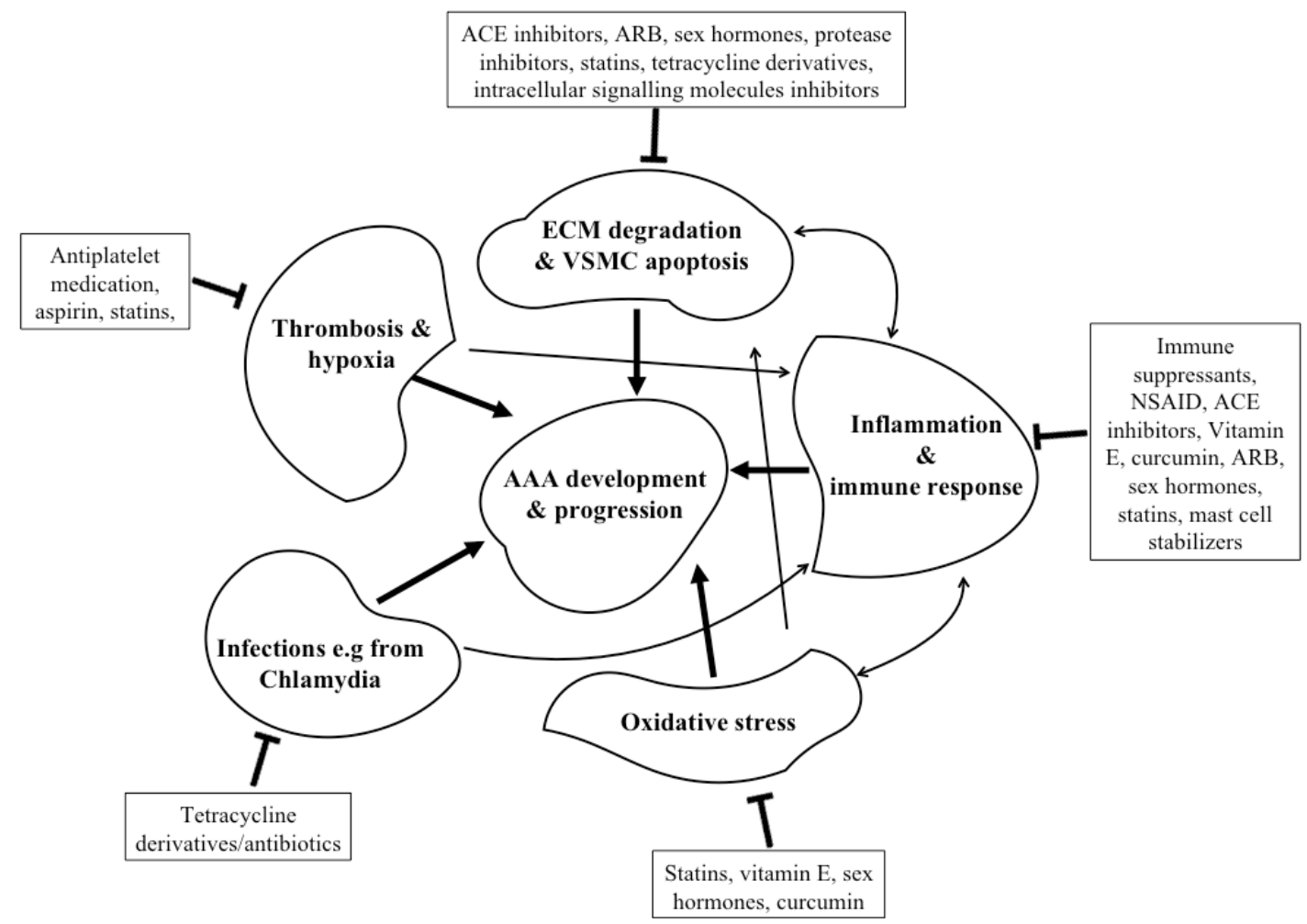

1192

1193 Figure 1. Current pharmacotherapeutic strategies/agents of relevance for abdominal aortic aneurysm (AAA) treatment. The flow chart shows key processes involved in AAA pathogenesis and potential therapeutic targets to deter AAA development and progression. ECM= extracellular matrix, VSMC= vascular smooth muscle cells, NSAID= non-steroidal anti-inflammatory drugs, ARB= angiotensin II receptor blocker 
1215 Table 1 Examples of studies assessing the effect of modulating the renin-angiotensin system on AAA

1216 development, progression and rupture

1217

\begin{tabular}{llll}
\hline Type of Study & Agent/Medication & Design & Effect on AAA \\
\hline Animal & $\begin{array}{l}\text { Enalapril, captopril and } \\
\text { lisinopril } \\
\text { Losartan }\end{array}$ & Elastase/rat(59) & Decreased development \\
& $\begin{array}{l}\text { Ang II/ ApoE }{ }^{-/-} \\
\text {/mice(60) }\end{array}$ & Decreased development \\
& Valsartan & $\begin{array}{l}\text { Elastase/rat(61) } \\
\text { Ang II/ ApoE }\end{array}$ & $\begin{array}{l}\text { Decreased development } \\
\text { Decreased progression }\end{array}$ \\
& Aliskiren & (mice(43) & \\
& Case-control(63) & $\begin{array}{l}\text { Decreased rupture } \\
\text { Increased risk of } \\
\text { progression }\end{array}$ \\
\hline ACEi & Cohort(64) & \\
\hline
\end{tabular}

1218

$\mathrm{ACEi}=$ angiotensin converting enzyme inhibitor; Ang II= angiotensin II; $\mathrm{ApoE}^{-/}=$apolipoprotein $\mathrm{E}$

1219 deficient

1220

1221

1222

1223

1224

1225

1226

1227

1228

1229

1230

1231

1232

1233

1234

1235

1236

1237

1238

1239

1240

1241

1242

1243

1244 
1245 Table 2 Examples of animal studies examining the effect modulating sex hormones on AAA

1246 development and severity

1247

\begin{tabular}{llll}
\hline Type of Study & Agent/Medication & Design & Effect on AAA \\
\hline Animal & $17 \beta$-estradiol & Elastase/rat(68) & Decreased development \\
$17 \beta$-estradiol & Ang II/ ApoE ${ }^{-/}$ & Decreased size \\
& /mice(69) & \\
& Tamoxifen & Ang II/ ApoE & \\
& Ovariectomy & Decreased development \\
& No effect \\
& Orchidectomy & Ang II/ ApoE & \\
& $/$mice(71) & Decreased development \\
& & \\
\hline
\end{tabular}

1248

Ang II= angiotensin II; ApoE ${ }^{-/}=$apolipoprotein E deficient

1249

1251

1252

1253

1254

1255

1256

1257

1258

1259

1260

1261

1262

1263

1264

1265

1266

1267

1268

1269

1270

1271

1272

1273

1274

1275

1276

1277

1278 
Table 3 Examples of studies assessing the effect of targeting inflammatory pathways on AAA

\begin{tabular}{|c|c|c|c|}
\hline Type of Study & Agent/Medication & Design & Effect on AAA \\
\hline \multirow[t]{9}{*}{ Animal } & Celecoxib & $\begin{array}{l}\text { Ang II/ } \mathrm{ApoE}^{-/-} \\
/ \text {mice(45) }\end{array}$ & $\begin{array}{l}\text { Decreased development } \\
\text { and severity }\end{array}$ \\
\hline & COX-2 deficiency & $\begin{array}{l}\text { Ang II/COX-2 }{ }^{-/} \\
/ \text {mice(82) }\end{array}$ & Decreased development \\
\hline & Indomethacin & Elastase/rat(83, 84) & $\begin{array}{l}\text { Decreased progression and } \\
\text { risk of rupture }\end{array}$ \\
\hline & Vitamin E & $\begin{array}{l}\text { Ang II/ } \mathrm{ApoE}^{-/-} \\
\text {/mice(89) }\end{array}$ & $\begin{array}{l}\text { Decreased progression and } \\
\text { rupture }\end{array}$ \\
\hline & & Elastase/rat(88) & Decreased progression \\
\hline & Curcumin & Elastase/mice(98) & Decrease development \\
\hline & Rapamycin & Elastase/rat(93) & Decreased progression \\
\hline & Everolimus & $\begin{array}{l}\text { Ang II/ ApoE } \\
\text { /mice(44) }\end{array}$ & Decreased development \\
\hline & $\begin{array}{l}\text { Methylprednisolone and } \\
\text { cyclosporine }\end{array}$ & Elastase/rat(94) & Decreased development \\
\hline \multirow[t]{2}{*}{ Human } & NSAID & Case-control(81) & Decreased progression \\
\hline & $\begin{array}{l}\text { Vitamin } \mathrm{E} \text { and } \beta \text { - } \\
\text { Carotene }\end{array}$ & RCT(90) & No effect on progression \\
\hline
\end{tabular}

Ang II= angiotensin II; $\mathrm{ApoE}^{-/}=$apolipoprotein $\mathrm{E}$ deficient: $\mathrm{COX}-2^{-/}=$cyclooxygenase 2 deficient; 
Table 4 Examples of studies assessing the effect of cholesterol lowering agents on AAA development and progression

\begin{tabular}{|c|c|c|c|}
\hline Type of Study & Agent/Medication & Design & Effect on AAA \\
\hline \multirow[t]{8}{*}{ Animal } & Simvastatin & 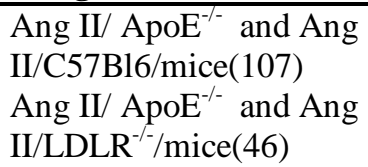 & $\begin{array}{l}\text { Decreased AAA } \\
\text { development } \\
\text { Limited effect }\end{array}$ \\
\hline & & Elastase/rat(110) & Decreased progression \\
\hline & Atorvastatin & Elastase/rat(113) & Decreased progression \\
\hline & & Elastase/rat(117) & $\begin{array}{l}\text { Limited effect on } \\
\text { progression }\end{array}$ \\
\hline & & $\begin{array}{l}\text { Ang II/ ApoE }{ }^{-/-} \\
/ \text {mice(118) }\end{array}$ & No effect \\
\hline & $\begin{array}{l}\text { Atorvastatin }+ \\
\text { amlodipine }\end{array}$ & $\begin{array}{l}\text { Ang II/ ApoE }{ }^{-/-} \\
/ \text {mice(118) }\end{array}$ & $\begin{array}{l}\text { Decreased } \\
\text { development }\end{array}$ \\
\hline & Fenofibrate & $\begin{array}{l}\text { Ang II/ ApoE }{ }^{-/-} \\
\text {/mice(48) }\end{array}$ & Decreased progression \\
\hline & & $\begin{array}{l}\text { Ang II/ LDLR }{ }^{-/} \\
/ \operatorname{mice}(119)\end{array}$ & Decreased progression \\
\hline \multirow[t]{4}{*}{ Human } & Statin & Retrospective(108) & Decreased progression \\
\hline & & Retrospective(122) & Decreased progression \\
\hline & & Cohort(126) & No effect \\
\hline & & Prospective(127) & $\begin{array}{l}\text { Potentially increased } \\
\text { development }\end{array}$ \\
\hline
\end{tabular}
density lipoprotein receptor deficient 
1332 1333 1334

\begin{tabular}{|c|c|c|c|}
\hline Type of Study & Agent/Medication & Design & Effect on AAA \\
\hline \multirow[t]{3}{*}{ Animal } & Fasudil & $\begin{array}{l}\text { Ang II/ ApoE }{ }^{-/-} \\
/ \text {mice(143) }\end{array}$ & $\begin{array}{l}\text { Decreased development } \\
\text { and severity }\end{array}$ \\
\hline & $\begin{array}{l}\text { 1,9-pyraloanthrone } \\
\text { (SP600125) }\end{array}$ & $\begin{array}{l}\text { Ang II/ } \mathrm{ApoE}^{-/-} / \text {mice } \\
\text { and } \mathrm{CaCl} 2 / \mathrm{mice}(139)\end{array}$ & Decreased development \\
\hline & $\begin{array}{l}\text { Pyrrolidine } \\
\text { dithiocarbamate (PDTC) }\end{array}$ & Elastase/rat(142) & $\begin{array}{l}\text { Decreased development } \\
\text { and size }\end{array}$ \\
\hline \multirow[t]{2}{*}{ Animal } & Doxycycline & Elastase/rat(172) & Decreased development \\
\hline & & Elastase/rat(173) & Decreased progression \\
\hline \multirow[t]{3}{*}{ Human } & Doxycycline & Prospective & $\begin{array}{l}\text { Limited effect on } \\
\text { progression }\end{array}$ \\
\hline & & Pilot(184) & Decreased progression \\
\hline & & RCT(188) & $\begin{array}{l}\text { Possibly increased } \\
\text { progression }\end{array}$ \\
\hline
\end{tabular}

Table 5 Examples of studies assessing the effect of targeting signalling pathways and proteases on AAA development and progression 